University of Louisville

ThinkIR: The University of Louisville's Institutional Repository

Electronic Theses and Dissertations

$5-2020$

\title{
The influence of self-forgiveness on relationship satisfaction post-infidelity.
}

Dominic Schmuck

University of Louisville

Follow this and additional works at: https://ir.library.louisville.edu/etd

Part of the Social Psychology Commons

\section{Recommended Citation}

Schmuck, Dominic, "The influence of self-forgiveness on relationship satisfaction post-infidelity." (2020). Electronic Theses and Dissertations. Paper 3474.

https://doi.org/10.18297/etd/3474

This Doctoral Dissertation is brought to you for free and open access by ThinkIR: The University of Louisville's Institutional Repository. It has been accepted for inclusion in Electronic Theses and Dissertations by an authorized administrator of ThinkIR: The University of Louisville's Institutional Repository. This title appears here courtesy of the author, who has retained all other copyrights. For more information, please contact thinkir@louisville.edu. 


\title{
THE INFLUENCE OF SELF-FORGIVENESS ON RELATIONSHIP SATISFACTION POST-INFIDELITY
}

\author{
By \\ Dominic Schmuck \\ B.S., Brigham Young University, 2014 \\ M.Ed., University of Louisville, 2016
}

A Dissertation Submitted to the Faculty of the College of Education and Human Development of University of Louisville in Partial Fulfillment of the Requirements for the Degree of

Doctor of Philosophy in Counseling and Personnel Services

\author{
Department of Counseling and Human Development \\ University of Louisville \\ Louisville, Kentucky
}

August 2020 

THE INFLUENCE OF SELF-FORGIVENESS ON RELATIONSHIP SATISFACTION POST-INFIDELITY

By

Dominic Schmuck

B.S., Brigham Young University, 2014

M.Ed., University of Louisville, 2016

A Dissertation Approved on

December 13, 2018

by the following Dissertation Committee:

Dissertation Director

Mark Leach, Ph.D.

Dissertation Co-Director

Anita Barbee, Ph.D.

Michael Cunningham, Ph.D.

Laurie McCubbin, Ph.D.

Amanda Mitchell, Ph.D. 


\title{
ABSTRACT \\ THE INFLUENCE OF SELF-FORGIVENESS ON RELATIONSHIP SATISFACTION POST-INFIDELITY
}

\author{
Dominic Schmuck
}

December 13, 2018

While a plethora of research studies exist regarding victims' healing processes postinfidelity, almost no empirical data is available regarding perpetrators' healing processes post-infidelity. In recent years, researchers have found that self-forgiveness after an interpersonal offense can aid individuals in healing intrapersonally and interpersonally. Self-forgiveness research even suggests a connection between genuine self-forgiveness and relationship satisfaction. The current study set out to explore the possible intrapersonal and interpersonal healing effects of self-forgiveness after participating in infidelity. For this study, individuals who participated in infidelity within the past two years and are still with the partner they betrayed were recruited. With support of affect theory of social exchange, a path model was hypothesized showing potential connections between self-forgiveness, intrapersonal affect, relationship closeness, relationship maintenance behaviors, and relationship satisfaction. Path model analyses revealed that genuine self-forgiveness was positively related to positive affect, closeness, positive maintenance behaviors, and relationship satisfaction. Simultaneously, pseudo selfforgiveness and self-punitiveness were positively related to negative affect and negative maintenance behaviors, and inversely related to closeness and relationship satisfaction. 
Limitations, future directions, and practical implications of the study findings are discussed. 


\section{TABLE OF CONTENTS}

CHAPTER I: INTRODUCTION..................................................

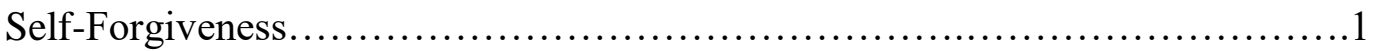

Self-Forgiveness and Intrapersonal Healing ................................5

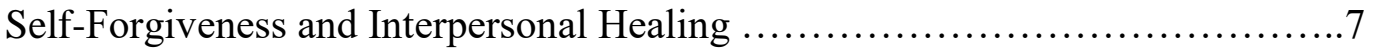

Affect Theory of Social Exchange............................................

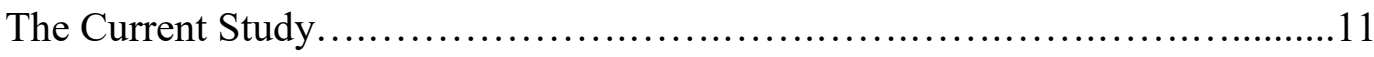

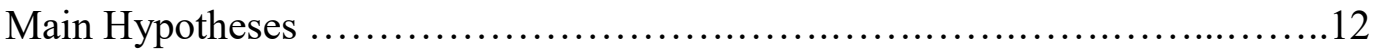

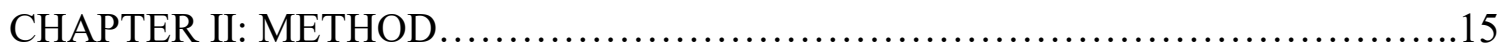

Procedure and Participants.............................................. 15

Measures............................................................................... 17

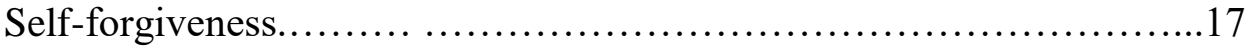

Positive and negative affect........................................ 18

Relationship closeness..........................................19

Positive maintenance behaviors.....................................19

Negative maintenance behaviors....................................20

Relationship satisfaction..............................................

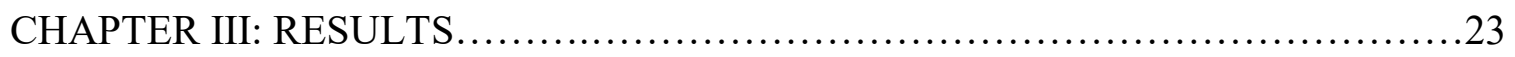

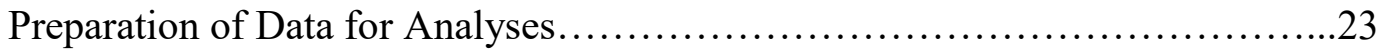

Testing of Control Variables.................................................

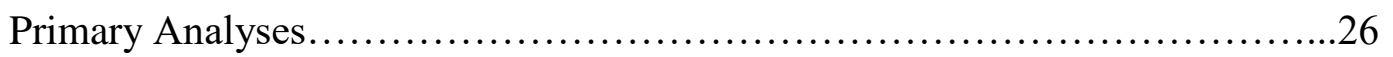




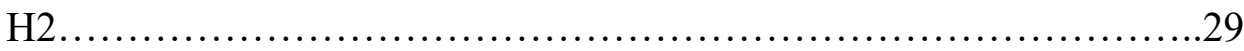

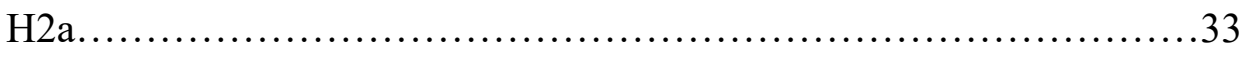

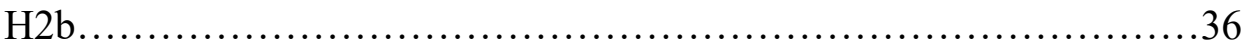

Supplementary Analyses............................................ 37

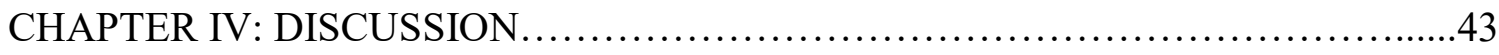

Limitations and Future Directions....................................47

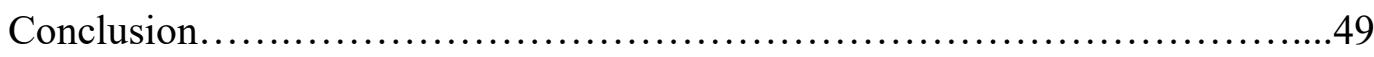

REFERENCES......................................................... 50

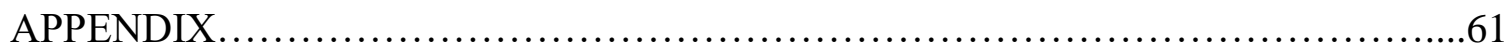

Discussion of Additional Analyses....................................62

Additional Tables with Demographic Information...........................65

Additional Path Analyses................................................68

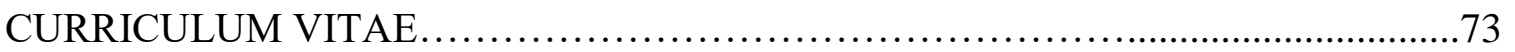




\section{LIST OF TABLES}

$\begin{array}{lll}\text { TABLE } & \text { PAGE }\end{array}$

Table1: Zero-order correlations between study variables and control variables..........25

Table 2: Zero-order correlation table of the study variables $\ldots \ldots \ldots \ldots \ldots \ldots \ldots \ldots \ldots \ldots . .27$

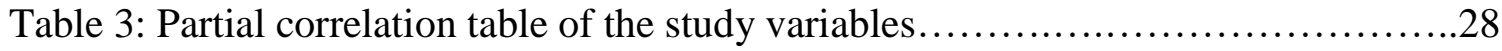

Table 4. Means of self-forgiveness constructs as a function of demographic variables...65

Table 5. Correlations of demographic variables with control and study variables.........66

Table 6. Intercorrelations of control variables.....................................67 


\section{LIST OF FIGURES}

$\begin{array}{ll}\text { FIGURE } & \text { PAGE }\end{array}$

Figure 1: Hypothesized model of the relationship between self-forgiveness and

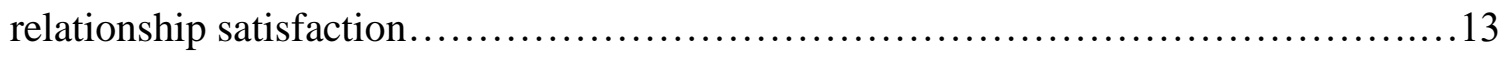

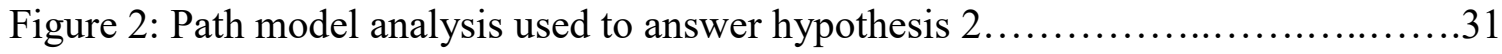

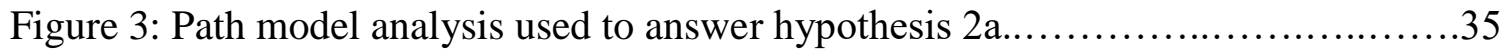

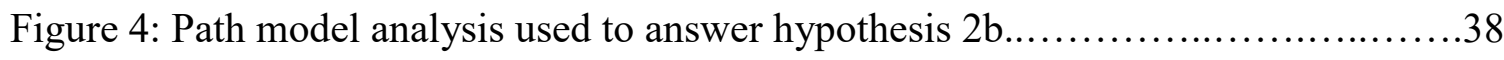

Figure 5: Path model analysis used for the supplementary analyses $\ldots \ldots \ldots \ldots \ldots \ldots \ldots \ldots . \ldots \ldots$

Figure 6: Path model analysis without correction by the control variables..............68

Figure 7: Path model analysis for individuals whose partners know of the affair........69

Figure 8: Path model analysis for individuals whose partners do not know of the affair..70

Figure 9. Path model analysis for females.................................. 71

Figure 10. Path model analysis for males....................................... 72 


\section{CHAPTER I: INTRODUCTION}

People often seek close connections to others, and most people desire to be a part of a committed romantic relationship because of the fulfillment it brings (Baumeister \& Leary, 1995). Some researchers have even argued that a committed romantic relationship is the closest relationship a human can enter (Berscheid, Snyder \& Omoto, 1989; Coccia \& Darling, 2014). Thus, romantic relationships have enormous potential to increase wellbeing, but betrayal and disappointment in romantic relationships can bring about serious negative emotional consequences as well (Berscheid \& Ammazzalorso, 2001). Infidelity within romantic relationships is considered one of the most serious relational offenses, most often negatively impacting emotional well-being of both partners, and frequently leading to relationship dissolution (Amato \& Perviti, 2003; Buss, 2000; National Fatherhood Initiative, 2005; Negash, Cui, Fincham, \& Pasley, 2014).

The association between decreased emotional well-being and increased relational distress of victims post-infidelity is clear, given that a plethora of studies have investigated this relationship (e.g.Fernandez, Vera-Villarroel, Sierra, \& Zubeidat, 2007; IJzerman et al., 2014). Additionally, researchers have also found that individuals participating in infidelity experiences decreased emotional well-being (e.g. elevated anxiety, depression, guilt, rumination) and increased relational distress post-infidelity (Evans, Ehlers, Mezey, \& Clark, 2007; Lawson \& Samson, 1988; Woodyatt \& Wenzel, 2013). Despite the negative effects infidelity has on offenders, victims, and on the committed relationship overall (Gordon \& Baucom, 1999), researchers have found that it 
occurs rather frequently. Various estimates regarding the prevalence of infidelity exist, but because infidelity is considered unacceptable by society (Blow \& Hartnett, 2005), it is still unclear whether estimates truly capture its prevalence.

For couples who decide to remain in their relationship post-infidelity, researchers have found that it is essential for victims to participate in forgiveness to rebuild satisfying relationships (e.g. Gordon, Baucom \& Snyder, 2004). While many studies exist regarding victims' experiences post-infidelity, little research is available regarding offenders' experiences. In the past few years, self-forgiveness researchers have proposed that offenders can participate in self-forgiveness after an interpersonal offense to bring about intrapersonal and interpersonal healing (Hall \& Fincham, 2005; Pelucchi, Paleari, Regalia, \& Fincham, 2013). Thus, this study investigated if self-forgiveness after infidelity may be an important piece that can bring about intrapersonal and interpersonal healing for infidelity offenders, similarly to how interpersonal forgiveness can bring about intrapersonal and interpersonal healing post-infidelity for victims. In brief, the current study investigated how self-forgiveness of offenders who remain with their partner post-infidelity influences intrapersonal healing, behaviors toward one's partner, and ultimately relationship satisfaction.

\section{Self-Forgiveness}

Because self-forgiveness has historically been a vastly understudied topic when compared with interpersonal forgiveness, Hall and Fincham (2005) entitled selfforgiveness "the stepchild of forgiveness research." When discussing self-forgiveness, it is essential to know that some researchers are currently focusing on three concepts of self-forgiveness. These three concepts are genuine self-forgiveness, pseudo self- 
forgiveness, and self-punitiveness, which Woodyatt and Wenzel (2013) proposed are three separate responses which an offender can exhibit after an offense.

When most individuals use the term self-forgiveness, they are likely referring to genuine self-forgiveness. Genuine self-forgiveness refers to individuals taking responsibility for the offense they have committed, putting time and effort into understanding what has lead them to their offense and making meaning of the event, and working through their guilt, shame, and self-resentment over time (Wenzel, Woodyatt, \& Hedrick, 2012). Usually, overcoming guilt, shame, and self-resentment through genuine self-forgiveness includes committing to avoiding the offense in the future and reconciling with the victim of the offense (Woodyatt \& Wenzel, 2013). Thus, genuine selfforgiveness is a process that takes time (Hall \& Fincham, 2005).

The end state of pseudo self-forgiveness may look similar to the end state of genuine self-forgiveness in that offenders exhibiting pseudo self-forgiveness do not, or only minimally, experience guilt, shame, or self-resentment because of their relational offense (Hall \& Fincham, 2005). However, instead of taking responsibility and processing their negative emotions, individuals exhibiting pseudo self-forgiveness avoid taking responsibility, and fully or partially blame their partner for their own offense. These individuals believe there is nothing to forgive oneself about (Woodyatt, Wenzel, \& Vel-Palumbo, 2017). Thus, individuals exhibiting pseudo self-forgiveness do not experience self-contempt and do not experience decreased self-regard, but experience contempt toward the person they offended (Wenzel et al., 2012). In their mind, the person they offended led them to the offense, and thus it is the other person's fault. Overall, pseudo self-forgiveness incorporates self-justification of one's offense. 
While some individuals may sway to the one extreme and completely avoid responsibility for the offense they have committed, other individuals may sway to the other extreme and become overwhelmed by their guilt, shame, and self-contempt that it is almost impossible for them to process their negative emotions through genuine selfforgiveness. These individuals exhibit self-punitiveness and become so overwhelmed by the negative emotions they experience post-offense, that they predominantly focus on themselves and their disdain for themselves (Wenzel et al., 2012). Self-punitive individuals may believe that they have done something wrong and are incapable of accepting their offense. Instead of repairing their relationship with the victim of their offense, they hope that self-punishing thoughts and or behaviors may rid them of their negative feelings toward themselves (Van Bunderen \& Bastian, 2014).

Studying the theoretical distinctions among genuine self-forgiveness, pseudo selfforgiveness, and self-punitiveness has expanded and advanced self-forgiveness research. Historically, researchers assumed that individuals who presented with lower selfcontempt or self-resentment post-offense had gone through a self-forgiveness process. However, this definition of self-forgiveness has yielded many contradictory findings. For example, Squires, Sztainert, Gillen, Caouette, and Wohl (2012) found that selfforgiveness does not predict behavioral change among alcoholics and gamblers, though, Sherer, Worthington, Hook, and Campana (2011), and Wohl, Pychyl, and Bennett (2010) found that self-forgiveness does predict behavioral change among alcoholics and procrastinating students. Part of the differences in findings may be related to the measurement of self-forgiveness. The researchers who found that self-forgiveness does not predict behavioral measured self-forgiveness by evaluating participants' lack of self- 
resentment. The researchers who found that self-forgiveness predicts behavioral change measured self-forgiveness by evaluating participants' lack of self-resentment and whether they took responsibility for their actions. The addition of responsibility with a lack of self-resentment may explain the contradictory findings between the mentioned studies.

Contradictory findings also exist for research that assesses self-forgiveness within interpersonal relationships. For example, Cohen (2011) and Kim, Johnson, and Ripley (2011) did not find a statistically significant relationship between self-forgiveness and relationship satisfaction, while Pelucchi et al. (2013), Pelucchi, Paleari, Regalia, and Fincham (2015), and Thompson et al. (2005) found a positive relationship between selfforgiveness and relationship satisfaction. Pelucchi et al. (2013) and Pelucchi et al. (2015) only used participants who indicated that they took responsibility for their offense, thus only capturing individuals participating in genuine self-forgiveness. These findings and many other contradictory findings within the self-forgiveness literature point to the conclusion that it is essential to distinctly evaluate genuine self-forgiveness, pseudo selfforgiveness, and self-punitiveness.

\section{Self-Forgiveness and Intrapersonal Healing}

Genuine self-forgiveness may serve as one way through which individuals can experience intrapersonal healing post-infidelity. As mentioned earlier, individuals participating in infidelity often experience increased guilt, shame, depression, anxiety, and generally decreased well-being and mental health (Evans et al., 2007; Lawson \& Samson, 1988;). Researchers found that individuals who take responsibility for an interpersonal offense they committed and actively practice self-forgiveness (i.e. exhibit genuine self-forgiveness) experience lower distress, anger, anxiety, sadness, heart rate, 
and guilt, and increased empathy and overall well-being post-offense (Cornish and Wade, 2015; da Sliva, Witvliet \& Riek, 2017; Kaye-Tzadok \& Davidson-Arad, 2016).

Pseudo self-forgiveness allows offenders to obtain some benefits similar to genuine self-forgiveness, in that offenders do not have to face negative emotions about themselves (Wenzel et al., 2012), because individuals exhibiting pseudo self-forgiveness do not (or only partially) take blame for their offense and thus avoid feelings of shame and guilt otherwise associated with an offense. In that sense, they can maintain a positive self-concept (Wohl, \& McLaughlin, 2014). However, individuals participating in pseudo self-forgiveness can experience negative emotions after an offense based on the relational difficulties they are experiencing which are blamed on their partner and, according to them, led them to commit their offense in the first place (Woodyatt \& Wenzel, 2013). This blaming of one's partner can lead to feelings of anger, frustration, hopelessness, and decreased positive emotions (Lawler, 2001).

Self-punitiveness post-offense may perpetuate and increase negative emotional experiences. Self-punitiveness is associated with guilt, shame, feeling negative about oneself, psychological distress, depression, and self-harm (Burke \& Haslam, 2001; Flett, Goldstein, Hewitt, \& Wekerle, 2012; Ingersoll-Dayton, Torges, Krause, 2010; Wenzel et al., 2012). Because self-punitiveness is associated with negative emotional experiences, it is considered maladaptive. Thus, dwelling on one's past behaviors to the extent that one is unable to overcome guilt and shame and is preoccupied with self-contempt, selfresentment, and self-condemnation, is not helpful for one's intrapersonal healing (Witvliet, Hinman, Eline, \& Brandt, 2011). 


\section{Self-Forgiveness and Interpersonal Healing}

The examination of self-forgiveness within the field of romantic relationships is still in its infancy. However, researchers have already found positive effects of selfforgiveness on one's romantic relationship, and Pelucchi et al. (2013) even suggested that genuine self-forgiveness may be an offender's way of dealing with an interpersonal transgression and improving relational bonds. To explain this idea further, an individual who does not exhibit genuine self-forgiveness may experience self-punitiveness and become so overwhelmed by guilt, shame, distress, and self-resentment (see Hall \& Fincham, 2005; Pelucchi et al., 2013) following their interpersonal offense, that they are unable to spend energy on their romantic partners or on improving one's relationship. Alternatively, an individual who does not exhibit genuine self-forgiveness may end up simply blaming their partner for their own interpersonal offense and would not see a need to participate in restorative behaviors. In an experimental study, Witvliet et al. (2011) found that individuals participating in the genuine self-forgiveness condition demonstrated increased motivation to exhibit reconciliatory behaviors toward the victim of their offense, individuals in the pseudo self-forgiveness condition did neither increase or decrease in their desire to participate in reconciliatory behaviors toward their victim, and individuals in the self-punitiveness condition had decreased motivation to participate in reconciliatory behaviors.

Some evidence exists that genuine self-forgiveness after a relational offense positively influence relationship satisfaction (Pelucchi et al., 2015). Briefly defined, relationship satisfaction refers to the affective overall evaluation of a relationship (Byers, 2005). Relationship satisfaction is essential for close relationships, as it predicts relational 
stability and safeguards against future acts of infidelity (Atkins et al., 2001; Fisher et al., 2006; Ruffieux, Nussbeck, \& Bodenmann, 2014). Funk and Rogge (2007) even stated relationship satisfaction to be the "cornerstone for our understanding of how relationships and marriages work" (p. 572).

To date, only two published studies have investigated how genuine selfforgiveness and unforgiveness influence relationship satisfaction post interpersonal offense. Pelucchi et al. (2013) and Pelucchi et al. (2015) investigated how selfforgiveness post interpersonal offense influences relationship satisfaction of self and partner. To screen out participants who participated in pseudo self-forgiveness instead of genuine self-forgiveness, the researchers asked participants to what extent they felt responsible for the wrongdoing. In both studies, the researchers found that offense specific genuine self-forgiveness positively influenced own relationship satisfaction, while unforgiveness of self (comparable to self-punitiveness) negatively influenced own relationship satisfaction and partner's relationship satisfaction.

While additional empirically published evidence regarding how offense specific genuine self-forgiveness, pseudo self-forgiveness, and self-punitiveness affect offenders' relationship satisfaction is not yet available, the evidence that self-forgiveness influences pro-relational behaviors also suggests that self-forgiveness influences relationship satisfaction. Multiple studies have found that pro-relational behaviors positively influence relationship satisfaction (e.g. Hesse, Pauley, \& Frye-Cox, 2015; Lawler, 2001; Weigel \& Ballard-Reisch, 2001). Thus, the overall research literature on self-forgiveness postinterpersonal offense suggests that genuine self-forgiveness has positive intrapersonal and interpersonal effects (McConnell, 2015). Because specific studies regarding self- 
forgiveness post-infidelity are not available, and because the mechanisms through which self-forgiveness affects relationship satisfaction are largely unknown, the current study sets out to answer these questions via a model from self-forgiveness to relationship satisfaction with the support of affect theory of social exchange.

\section{Affect Theory of Social Exchange}

Affect theory of social exchange posits that emotions (affects) provide individuals with reinforcements or punishments regarding relational (exchange) behaviors (Lawler, 2001). According to Lawler (2001) emotions operate along positive and negative evaluative states. Individuals seek to exhibit more behaviors associated with positive emotions, as those provide reinforcements, and to participate in fewer behaviors resulting in negative emotions, as those provide punishments. Social exchanges influence individuals' global emotional experiences (Lawler, 2001; Molm, 1994). Global emotional experiences refer to an individual's overall everyday feelings and emotions. These global emotions have ambiguous sources. Specific emotions refer to feelings an individual has about a specific social object (e.g. self, other, relationship), meaning that the source of specific emotions appears clear to an individual. According to affect theory of social exchange, individuals are motivated to rationally examine the source (e.g. self, other, relationship) of global emotions, and then tie specific emotions to that source (Lawler, 2001).

Global emotions are produced by social exchanges. Affect theory of social exchange posits that individuals experiencing positive or negative emotions will at least in part attribute those positive or negative emotions to their relationship with another with whom they are in exchanges (Lawler, 2001; Lawler \& Yoon, 1996). Berscheid and 
Ammazzalorso (2001) also suggested that individuals are prone to let their emotional states outside of their relationship (global emotions) influence their emotional state inside their relationship (specific emotion). Berscheid and Ammazzalorso (2001) referred to this as emotion spillover. The assumption and theory behind emotion spillover is also backed by empirical evidence (e.g. Forgas, Levinger, \& Moylan, 1994).

According to affect theory of social exchange, when individuals interpret negative global emotions to stem from a specific source, they experience less closeness or cohesion to that source. On the other hand, when individuals interpret positive global emotions to stem from a specific source, they experience increased closeness or cohesion to that source (Lawler, 2001; Forgas et al., 1994). Affect theory of social exchange posits that individuals experiencing positive or negative emotions will at least in part attribute those positive or negative emotions to their committed relationship which leads to increased or decreased closeness (Lawler, \& Yoon, 1996; Lawler, 2001). Kelley et al. (1983), Berscheid et al. (1989), and Berscheid and Ammazzalorso (2001) conceptualized closeness within a relationship as the degree to which partners are interdependent. In other words, closeness refers to the degree to which one partner's actions influence another partner's actions emotionally, cognitively, and behaviorally. Affect theory of social exchange and longitudinal research evidence suggest that the closer individuals feel to their partner, the more positive behaviors they will exhibit to maintain their relationship and the fewer negative behaviors they will exhibit (Lawler, 2001; Ledbetter, 2009; Riek, Luna, \& Schnabelrauch, 2014).

According to affect theory of social exchange, individuals exhibiting positive maintenance behaviors toward their partner promote positive emotional feedback from 
their partner which elicits positive judgments regarding one's relationship, thus increasing relationship satisfaction (Lawler, 2001). At the same time, individuals exhibiting negative maintenance behaviors (i.e. behaviors that are intended to maintain a relationship in its current state or to sustain desired relational definitions while being negative in nature [Canary \& Stafford, 1994]) promote negative emotional feedback from their partner which elicits negative judgments regarding one's relationship, thus decreasing relationship satisfaction (Lawler, 2001).

Longitudinal research studies support the directionality of individual behavior toward one's partner affecting one's level of satisfaction, as proposed by affect theory of social exchange (e.g. Johnson et al., 2005; Kiecolt-Glaser, Bane, Glaser, \& Malarkey, 2003). For example, Huston and Vangelisti (1991) found that individuals' behaviors toward their partner predicted latter relationship satisfaction levels, while satisfaction levels did not predict latter behaviors toward one's partner. Similarly, McNulty and Russell (2010) found that negative communication behaviors predicted latter decline in relationship satisfaction at 6-8 month follow up.

\section{The Current Study}

Theoretical and empirical evidence suggests that infidelity offenders who desire to remain with their committed romantic partner would benefit from genuine selfforgiveness to improve their interpersonal functioning with their romantic partner, and to improve their feelings toward their relationship. At the same time, individuals exhibiting self-punitiveness and pseudo self-forgiveness may harm their relationship. The current study set out to examine the relationship between self-forgiveness and relationship satisfaction. 
The model seen in Figure 1 was proposed via the aid of affect theory of social exchange, outlining the relationship between self-forgiveness, and relationship satisfaction. Theoretical and empirical evidence suggests that offender's self-forgiveness would impact their overall emotional/affective experience. Offenders would at least in part attribute this change in their affective state as a result of self-forgiveness to their partner, thus increasing or decreasing (depending on their affective experience) perceived closeness to their romantic partner. When individuals feel closer to their partner, they will engage in more positive relational maintenance behaviors and fewer negative relational maintenance behaviors toward their romantic partners. These positive or negative behaviors, social exchanges, will directly impact offenders' satisfaction with their relationship.

\section{Main Hypotheses}

This study tested the following hypotheses for individuals who remained with the partner they betrayed. Hypothesis 1 (labeled H1) states that self-forgiveness (i.e. genuine self-forgiveness, pseudo self-forgiveness, and self-punitiveness) post-infidelity will be significantly related to offender's affective states (i.e. positive and negative affect), relational closeness, relational behaviors (i.e. positive and negative relational maintenance behaviors), and relationship satisfaction. Hypothesis 2 (labeled H2) states that offenders' affective states (i.e. positive and negative affect), relational closeness, and relational behaviors (i.e. positive and negative relational maintenance behaviors), will fully mediate the relationship between self-forgiveness (i.e. genuine self-forgiveness, pseudo self-forgiveness, and self-punitiveness) post-infidelity and relationship satisfaction. Hypothesis $2 \mathrm{a}$ (labeled H2a) states that positive affect and negative affect 


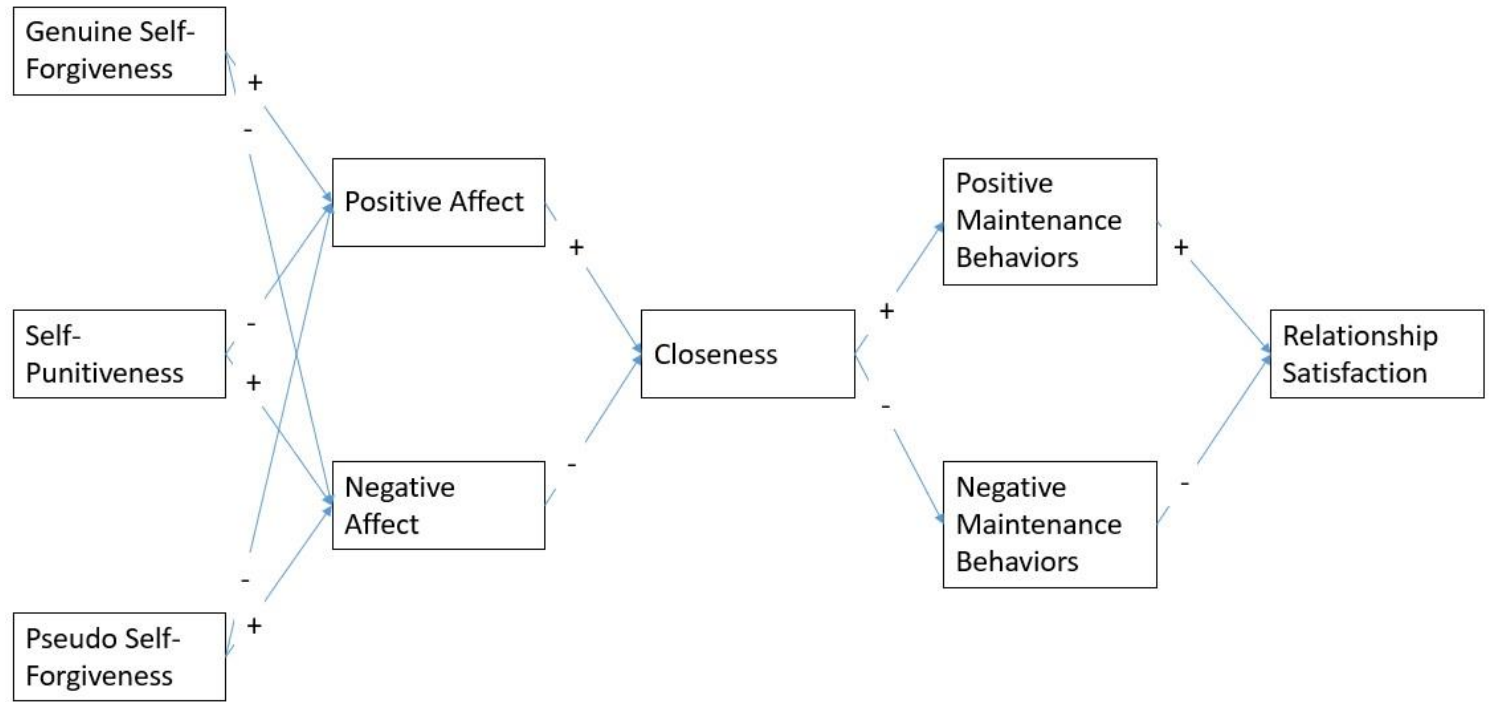

Figure 1. Hypothesized model of the relationship between self-forgiveness and relationship satisfaction. 
will fully mediate the relationship between self-forgiveness (i.e. genuine self-forgiveness, pseudo self-forgiveness, and self-punitiveness) and relational closeness. Last, Hypothesis $2 \mathrm{~b}$ (labeled $\mathrm{H} 2 \mathrm{~b}$ ) states that positive and negative maintenance behaviors will fully mediate the relationship between closeness and relationship satisfaction. 


\section{CHAPTER II: METHOD}

\section{Procedure and Participants}

Data analysis was performed on individuals who participated in infidelity outside their current committed romantic relationship since their $18^{\text {th }}$ birthday, and who were at the time of the study not participating in an extra relational affair. Additionally, participants participated in their most recent act of infidelity within the past 2 years. Participants were recruited through Amazon's Mechanical Turk (MTurk). MTurk is an online marketplace hosted by Amazon.com, where individuals called "workers" can choose to participate in varying tasks for monetary compensation. For this study, participants were paid $\$ 1$ for completing the survey. Researchers found that MTurk participants are more ethnically and socio-economically diverse than participants recruited through other online means (Casler, Bickel, \& Hackett, 2013) while still producing equal or even better quality work (Hauser \& Schwarz, 2016). Overall, Baumeister, Kwang, and Gosling (2011) concluded that MTurk participants provide quick high-quality data at a very inexpensive price point. In total, 501 individuals completed the survey, fit all inclusion criteria ${ }^{1}$ (whether survey takers fit inclusion criteria was assessed during the first 6 questions of the survey), and correctly answered

\footnotetext{
${ }^{1}$ The inclusion criteria for this study were: Participants had to participate in infidelity since the age of 18 , were (at the time of the study) not participating in an extrarelational affair, were part of a monogamous relationship during their infidelity, did not have permission by their partner to participate in an extrarelational affair, participated in their most recent act of infidelity within the past 2 years, and were (at the time of the study) still with the same partner they were with before their most recent affair.
} 
all attention questions. The median completion time was 12 minutes and 4 seconds. To remove speeders (see Ford, 2017; Kees et al., 2017) from the survey who may have made it through all implemented survey strategies to weed out faulty responses, responses from individuals who took less than 6 minutes (i.e. half the median survey completion time) to complete the survey were deleted (46 cases). After also removing 2 outliers, the final sample consisted of 453 participants. $^{2}$

Of the sample, $51.6 \%$ identified as male, $47.5 \%$ identified as female, $.2 \%$ identified as transgender female, . $4 \%$ identified as nonbinary, and $.2 \%$ identified as other. Additionally, $79.6 \%$ identified as heterosexual, $16.5 \%$ identified as bisexual, $1.5 \%$ identified as lesbian, $1.1 \%$ identified as gay, $1.1 \%$ identified as pansexual, and .2\% identified as other. The age range of the participants was $18-60$ with the median age of 29. Participants' median relationship duration with their partner was 3 years and 4 months (range is 1 month to 33 years). The median amount of time passed since participants' last act of infidelity was 1 year (range is less than 1 month to 2 years). Participants' median affair duration was 6 months (range is 1-time occurrence to 9 years and 6 months). At the time of participants' most recent infidelity, $36.7 \%$ of the participants were married, $34.3 \%$ of the participants were cohabiting, and $29.1 \%$ of the participants were in a dating relationship. At the time of the survey response collection, $44.0 \%$ of the participants were married, $35.8 \%$ were cohabiting, and $20.2 \%$ were in a

\footnotetext{
${ }^{2}$ The 6-question screening questionnaire was completed by 2374 individuals who fit all inclusion criteria except whether their most recent act of infidelity occurred within the past 2 years, and whether they were still with the same partner. Of those participants $50.2 \%$ are still with the same partner they were with before the infidelity, $19.3 \%$ are in a relationship with a new person, $15.0 \%$ are single, and $11.1 \%$ are in a relationship with the person they had the affair with. Of the 2374 participants, 1044 participants committed their most recent act of infidelity within the past 2 years. Of these participants $60.0 \%$ are still with the same partner they were with before the infidelity, $15.5 \%$ are in a relationship with a new person, $15.3 \%$ are single, and $9.2 \%$ are in a relationship with the person they had the affair with.
} 
dating relationship, indicating that some individuals changed their relationship status since the infidelity while still being in a committed relationship with the same partner. Of the sample, $44.6 \%$ participated in emotional and sexual infidelity, $34.9 \%$ participated in sexual infidelity only, and $20.4 \%$ participated in emotional infidelity only. Of the participants' partners, 50.5\% know about the infidelity. The participants' ethnicity distribution was: White/Caucasian 55.4\%, Asian 21.1\%, Black/African 11.4\%, Hispanic/Latino 7.3\%, American Indian/Alaska Native 1.5\%, Multicultural 1.5\%, and other $1.7 \%$.

\section{Measures}

Self-forgiveness. Woodyatt and Wenzel (2013) developed the Differentiated

Process Scale of Self-Forgiveness, which consists of three subscales; genuine selfforgiveness (7 items), pseudo self-forgiveness ( 6 items), and self-punitiveness (6 items). Example items of genuine self-forgiveness include "Since committing the offense I have tried to change" and "I have tried to think through why I did what I did." Example items of pseudo self-forgiveness include "I wasn't the only one to blame for what happened" and "I am not really sure whether what I did was wrong." Example items of selfpunitiveness include "I can't seem to get over what I have done" and "I deserve to suffer for what I have done." All items are scored on a 7-point Likert scale, where $1=$ Do not agree at all, and $7=$ Strongly agree . Woodyatt \& Wenzel (2013) established construct validity via confirmatory factor analysis (CFA), and tested correlations with the related constructs of guilt, anger, shame, responsibility taking, and self-acceptance.

The original instructions for the measure were slightly modified to fit the research question. Instead of thinking about an act of interpersonal transgression committed during 
the past week (Woodyatt \& Wenzel, 2013), participants in this study were instructed to think about their most recent act of infidelity. For the current sample, $\alpha=.88$ for genuine self-forgiveness, $\alpha=.91$ for self-punitiveness, and $\alpha=.85$ for pseudo self-forgiveness

Positive and negative affect. Watson, Clark, and Tellegen (1988) developed the Positive and Negative Affect Schedule (PANAS), which consists of two subscales (Positive Affect and Negative Affect) measured by 10 items each. Sample items/emotions for the positive affect subscale include "interested", "excited", and "enthusiastic", while sample items/emotions for the negative affect subscale include "irritable", "ashamed", and "nervous." All items are scored on a 5-point Likert scale, where $1=$ Very Slightly or Not at All, $2=$ A Little, $3=$ Moderately, $4=$ Quite a Bit, and $5=$ Extremely. The researchers examined the PANAS construct validity via CFA and found that it was adequate. The PANAS subscales were found to demonstrate strong discriminant validity (Armitage \& Harris, 2006) and strong convergent validity to measures of anxiety and depression (Crawford \& Henry, 2004; Watson et al., 1988) among the general population.

For this study, participants were asked twice via slightly modified instructions to indicate to what extent they felt certain emotions over the past few weeks. In version 1 participants were asked to indicate in general to what extent they felt certain emotions over the past few weeks, while in version 2 they were asked to what extent they felt certain emotions over the past few weeks while they were with their partner. The order in which version 1 and version 2 appeared in the survey was randomized. For the current sample, $\alpha=.91$ for positive affect of both versions, $\alpha=.94$ for negative affect of both versions. Positive affect (version 1) was correlated with positive affect while with one's partner (version 2) at .81, while negative affect (version 1) was correlated with negative 
affect while with one's partner (version 2) at .87. Because version 2 demonstrated slightly improved correlations with the other study variables, version 2 was used throughout the rest of the study.

Relationship closeness. The Unidimensional Relationship Closeness Scale (URCS) developed by Dibble, Levine, and Park (2012) was used to evaluate relational closeness. The URCS consists of 12 items measured on a 7 point-Likert type scale where $1=$ Strongly Disagree and $7=$ Strongly Agree. Sample items include "My relationship with my romantic partner is close" and "My romantic partner and I have a strong connection.” The researchers established construct validity by taking items from previous established relationship closeness measures and creating items intended to capture the dual aspects of behaving and feeling close. Additionally, the researchers performed CFA analyses on individuals in four different relationship types (i.e. romantic relationship, family members, friends, strangers). Discriminant validity was established by demonstrating that relationship satisfaction items loaded onto a different factor than the URCS items did, and convergent validity was established by demonstrating that Inclusion of the Other in the Self (IOS) items loaded onto the same factor as the UCRI items. For the current sample, $\alpha=.96$.

Positive maintenance behaviors. The Relational Maintenance Strategy Measure (RMSM), developed by Stafford and Canary (1991) and refined by Canary and Stafford (1992) was used to assess positive relational maintenance behaviors. The RMSM consists of 29 items measured on a 7 point-Likert type scale where $1=$ Strongly Disagree and $7=$ Strongly Agree. Sample items include "I attempt to make our interactions very enjoyable" and "I disclose what I need or want from our relationship." The RMSM has five 
subscales. These subscales are assurance, openness, positivity, sharing tasks, and social networks. Canary, Stafford, and Semic (2002) concluded that face validity, predictive validity, discriminate validity, and construct validity have all been demonstrated in numerous studies using the RMSM. For this study, CFA was utilized to confirm that the five RMSM subscales (in the current sample $\alpha=.91$ for positivity, $\alpha=.90$ for openness, $\alpha=.84$ for assurance, $\alpha=.89$ for network, and $\alpha=.90$ for sharing tasks) appropriately loaded onto an overall positive maintenance behavior factor. CFA analyses revealed that the positivity and sharing tasks subscales have shared commonality (i.e. model fit improved by correlating their error terms). The model had excellent fit to the data $\chi^{2}(4)=$ $1.56, p=.82$, Confirmatory Fit Index $(\mathrm{CFI})=1.00$, Tucker Lewis Index $(\mathrm{TLI})=1.00$, Root Mean Square Error of Approximation $($ RMSEA $)=.00$, PClose $=.97$. Thus, positivity, openness, assurance, network, and tasks, appropriately measured an overall positive maintenance behaviors factor. Additionally, when testing the reliability of the RMSM items among the current sample, $\alpha=.95$ indicating that RMSM items consistently measured positive maintenance behaviors.

Negative maintenance behaviors. The Negative Maintenance Scale (NMS), developed by Dainton and Gross (2008), was used to assess negative relational maintenance behaviors. The Negative Maintenance Scale consists of 20 items measured on a 7-point Likert type scale $(1=$ Strongly Disagree, $7=$ Strongly Agree $)$. Sample items include "I flirt with others to make my partner jealous" and "I start arguments with my partner." The NMS has six subscales, which are jealousy induction, avoidance, spying, infidelity, destructive conflict, and allow control. For this study, CFA was utilized to confirm that the six NMS subscales (in the current sample $\alpha=.93$ for jealousy induction, 
$\alpha=.83$ for avoidance, $\alpha=.90$ for spying, $\alpha=.84$ for infidelity, $\alpha=.89$ for destructive conflict, and $\alpha=.89$ for allow control) appropriately measured negative relational maintenance behaviors. CFA analyses revealed that the jealousy induction and infidelity subscales, as well as the avoidance and allowing control subscales have shared commonality (i.e. model fit improved by correlating their error terms). The model had good fit to the data $\chi^{2}(7)=18.81, p=.01, \mathrm{CFI}=.993, \mathrm{TLI}=.985, \mathrm{RMSEA}=.06$, PClose $=.249$. Thus, jealousy induction, avoidance, spying, infidelity, destructive conflict, and allow control, appropriately measured an overall negative maintenance behaviors factor. Additionally, $\alpha=.95$ for the NMS items, indicating that NMS items consistently measured negative maintenance behaviors.

Relationship satisfaction. Funk and Rogge (2007) developed the Couples Satisfaction Index (CSI) by administering all items (total of 180 items) from eight wellestablished relationship satisfactions scales to over 6000 participants, and then used Item Response Theory analysis to develop a 32-item measure. Example items of the measure include "To what extent has your relationship met your original expectations" and "Do you enjoy your partner's company." Some items on the scale are scored on a 6-point Likert scale, and others are scored on a 7-point Likert scale. Continuous scoring is used to calculate the overall CSI score. Funk and Rogge (2007) found that the CSI scale demonstrates strong convergent validity with the eight most commonly used relationship satisfaction scales (e.g. Dyadic Adjustment Scale [DAS], Marital Adjustment Test [MAT], Quality of Marriage Index). Item Response Theory analysis demonstrated that the CSI measures the same constructs as the widely-accepted DAS and MAT 
(demonstrating construct validity), but with much more power and precision. For the current sample $\alpha=.95$. 


\section{CHAPTER III: RESULTS}

\section{Preparation of Data for Analyses}

Relevant assumptions were tested, and the data was cleaned before conducting statistical analyses. Path model analyses and SEM are robust against violations of nonnormally distributed variables (O’Rourke \& Hatcher, 2013). None of the model variables had skewness or kurtosis below -2 or above +2 , indicating acceptable normal distributions of the study variables (Field, 2009; Gravetter \& Wallnau, 2014). Linear relationships between dependent and independent variables were visually inspected and found acceptable. The assumption of multicollinearity was also not found to be violated as all independent study variable correlations were below .8 (O'Rourke \& Hatcher, 2013). However, closeness correlated with the dependent variable (i.e. satisfaction) at .81 indicating strong overlap in the current sample. Excluding the 6 items (2 from closeness and 4 from satisfaction) that contributed the most to the closeness and satisfaction correlation decreased the correlation from .81 to .78. Similarly, factor analyzing the closeness and satisfaction items together and excluding items with the strongest cross loadings also did not significantly reduce the closeness-satisfaction correlation. Because of this, item exclusions were not retained. Combining the satisfaction and closeness factors into one factor in the current study would, however, be opposed to theoretical and empirical distinctions that have been drawn between relationship closeness and relationship satisfaction (Aron, Aron, \& Smollan, 1992; Dibble et al, 2012). To inspect potential outliers and influential data points, studentized residuals and cooks-d values 
were calculated and standardized residuals vs standardized predicted values plots were visually inspected. Two cases were excluded from further analyses because of high cooks-d values (14.60 and 9.25), high studentized residual values (3.76 and 3.95), and visual inspection also revealing these two points as outliers.

\section{Testing of Control Variables}

The main effects of five a priori defined potential control variables were evaluated on each of the nine study variables (for the zero-order correlations between the study variables and the control variables see Table 1). The control variables were type of infidelity (dummy coded for whether individuals participated in emotional infidelity or sexual infidelity or emotional and sexual infidelity ${ }^{3}$ ), time passed since the infidelity, duration of the infidelity, whether the partner knows of the infidelity, and length of time in one's relationship. Via regression analysis, the main effects (reported below) of the control variables on the study variables were evaluated to see to what extent they influenced each study variable above and beyond the hypothesized predictor variables. Whether the partner knows of the affair was significantly related to genuine selfforgiveness $(\beta=.18, p<.001)$. In comparison to individuals engaging in sexual and emotional infidelity, whether an individual engaged in emotional infidelity was negatively related with self-punitiveness $(\beta=-.14, p=.01)$, pseudo self-forgiveness $(\beta=$ $-.10, p=.05)$, and negative maintenance behaviors $(\beta=-.16, p<.01)$. In comparison to individuals engaging in sexual and emotional infidelity, whether an individual engaged in sexual infidelity was negatively related with self-punitiveness $(\beta=-.22, p<.001)$, pseudo

\footnotetext{
${ }^{3}$ Three dummy variables were created to account for the variance of emotional infidelity, sexual infidelity, and emotional and sexual infidelity. One with emotional infidelity equaling 1 and other infidelity equaling 0 , one with sexual infidelity equaling 1 and other infidelity equaling 0 , and one with emotional and sexual infidelity equaling 1 and other infidelity equaling 0 .
} 
Table 1. Zero-order correlations between study variables and control variables

\begin{tabular}{|c|c|c|c|c|c|c|c|}
\hline & EI & SI & ESI & LA & $\mathrm{AD}$ & $\mathrm{RD}$ & PK \\
\hline GS & .07 & -.08 & .02 & -.07 & .06 & .02 & $.19 * * *$ \\
\hline SP & -.06 & $-.18 * * *$ & $.22 * * *$ & .06 & $.15^{* *}$ & $-.21 * * *$ & .07 \\
\hline PS & -.01 & $-.23 * * *$ & $.23 * * *$ & $.10 *$ & $.13 * *$ & $-.15 * *$ & .03 \\
\hline PA & -.04 & -.08 & $.11^{*}$ & .06 & $.13 * *$ & $-.18 * * *$ & .05 \\
\hline NA & -.01 & $-.15 * *$ & $.15 * *$ & .08 & $.16^{* * * *}$ & $-.18 * * *$ & $.12 *$ \\
\hline $\mathrm{C}$ & .00 & .02 & -.02 & -.06 & .01 & -.07 & .01 \\
\hline PMB & .00 & -.01 & .01 & -.04 & .00 & -.06 & .05 \\
\hline NMB & -.08 & $-.19 * * *$ & $.24 * * *$ & .09 & $.15^{* *}$ & $-.21 * * *$ & .01 \\
\hline $\mathrm{RS}$ & .02 & .05 & -.07 & -.05 & .02 & -.06 & .00 \\
\hline
\end{tabular}

Note. $\mathrm{N}=453, * p<.05, * * p<.01, * * * p<.001 . \mathrm{GS}=$ Genuine Self-Forgiveness, $\mathrm{SP}=$ SelfPunitiveness, PS = Pseudo Self-Forgiveness, PA = Positive Affect, NA = Negative Affect, $\mathrm{C}=$ Closeness, PMB = Positive Maintenance Behaviors, NMB = Negative Maintenance Behaviors, RS = Relationship Satisfaction, EI= Emotional Infidelity, SI = Sexual Infidelity, ESI = Emotional and Sexual Infidelity, LA = Time passed since the Last Affair, $\mathrm{AD}=$ Affair Duration, $\mathrm{RD}=$ Relationship Duration, $\mathrm{PK}=$ Partner Knows of the infidelity. 
self-forgiveness $(\beta=-.26, p<.001)$, and negative maintenance behaviors $(\beta=-.24, p$ $<.001)$. In comparison to individuals engaging in emotional infidelity, whether an individual engaged in sexual infidelity was negatively related with pseudo selfforgiveness ( $\beta=-.15, p=.02$ ). How long the affair lasted was significantly related to self-punitiveness ( $\beta=.14, p<.01)$, pseudo self-forgiveness $(\beta=.10, p=.04)$, positive affect $(\beta=.11, p=.02)$, negative maintenance behaviors $(\beta=.15, p<.001)$, and relationship satisfaction $(\beta=.08, p=.03)$. Length of time in one's relationship was negatively related with self-punitiveness $(\beta=-.24, p<.001)$, pseudo self-forgiveness $(\beta=$ $-.19, p<.001)$, positive affect $(\beta=-.17, p<.001)$, negative maintenance behaviors $(\beta=$ $-.26, p<.001)$, and relationship satisfaction $(\beta=-.09, p=.01)$. How long ago the affair occurred was not significantly related to any of the nine study variables above and beyond the other control variables and hypothesized predictor variables. Because of this, how long ago the affair occurred was not used as a control variable in this study.

\section{Primary Analyses}

First, a zero-order correlation table of the nine study variables was created (see Table 2). Next, a partial correlation table was created including the nine study variables while controlling for type of infidelity, duration of the infidelity, whether the partner knows of the infidelity, and length of time in one's relationship (see Table 3). Comparing the zero-order correlation table (Table 2) to the partial correlation table (Table 3) shows that negative affect correlated significantly with positive affect in the zero-order correlation table $(r=.11, p=.02)$, but the two variables were not significantly correlated in the partial correlation table $(r=.03, p=.50)$. 
Table 2. Zero-order correlation table of the study variables

\begin{tabular}{|c|c|c|c|c|c|c|c|c|}
\hline & 1 & 2 & 3 & 4 & 5 & 6 & 7 & 8 \\
\hline 1. GS & - & & & & & & & \\
\hline 2. SP & $.38 * * *$ & - & & & & & & \\
\hline 3. PS & $-.21 * * *$ & $.27 * * *$ & - & & & & & \\
\hline 4. PA & $.23 * * *$ & $.26 * * *$ & .09 & - & & & & \\
\hline 5. NA & $.14 * *$ & $.58 * * *$ & $.51 * * *$ & $.11^{*}$ & - & & & \\
\hline 6. $\mathrm{C}$ & $.43 * * *$ & $.12 *$ & $-.23 * * *$ & $.52 * * *$ & $-.11 *$ & - & & \\
\hline 7. PMB & $.47 * * *$ & $.13^{* *}$ & $-.15 * * *$ & $.53 * * *$ & -.06 & $.79 * * *$ & - & \\
\hline 8. NMB & .02 & $.52 * * *$ & $.65 * * *$ & $.21 * * *$ & $.69 * * *$ & -.07 & -.09 & - \\
\hline 9. RS & $.41 * * *$ & .04 & $-.37 * * *$ & $.52 * * *$ & $-.28 * * *$ & $.82 * * *$ & $.66 * * *$ & $-.26 * * *$ \\
\hline $\begin{array}{l}\text { Note. } \mathrm{N}= \\
\text { Punitiver } \\
\text { Affect, } \mathrm{C}\end{array}$ & $\begin{array}{l}453,{ }^{*} p< \\
\text { less, PS } \\
=\text { Close }\end{array}$ & $\begin{array}{l}{ }^{* * p<} \text {. } \\
\text { seudo S } \\
\text { s, PMB }\end{array}$ & $\begin{array}{l}01, * * * p \\
\text { elf-Forgi } \\
=\text { Positiv }\end{array}$ & $\begin{array}{l}01 . \mathrm{GS} \\
\text { ness, P } \\
\text { Mainter }\end{array}$ & $\begin{array}{l}=\text { Genuin } \\
=\text { Positi } \\
\text { lance Beh }\end{array}$ & $\begin{array}{l}\text { Self-For } \\
\text { e Affect, } \\
\text { aviors, NN }\end{array}$ & $\begin{array}{l}\text { giveness, } \\
\mathrm{NA}=\mathrm{Ne} \\
\mathrm{MB}=\mathrm{Ne}\end{array}$ & $\begin{array}{l}\mathrm{SP}=\text { Self } \\
\text { gative } \\
\text { ative }\end{array}$ \\
\hline
\end{tabular}


Table 3. Partial correlation table of the study variables

\begin{tabular}{|c|c|c|c|c|c|c|c|c|}
\hline & 1 & 2 & 3 & 4 & 5 & 6 & 7 & 8 \\
\hline 1. GS & - & & & & & & & \\
\hline 2. SP & $.39 * * *$ & - & & & & & & \\
\hline 3. PS & $-.24 * * *$ & $.19 * * *$ & - & & & & & \\
\hline 4. PA & $.23 * * *$ & $.19 * * *$ & .02 & - & & & & \\
\hline 5. NA & $.12 *$ & $.54 * * *$ & $.47 * * *$ & .03 & - & & & \\
\hline 6. $\mathrm{C}$ & $.44 * * *$ & $.11 *$ & $-.25 * * *$ & $.53 * * *$ & $-.14 * *$ & - & & \\
\hline 7. $\mathrm{PMB}$ & $.48 * * *$ & $.12 *$ & $-.17 * * *$ & $.54 * * *$ & -.08 & $.79 * * *$ & - & \\
\hline 8. NMB & .02 & $.46 * * *$ & $.61 * * *$ & $.14 * *$ & $.66 * * *$ & -.09 & -.09 & - \\
\hline 9. RS & $.42 * * *$ & .04 & $-.39 * * *$ & $.53 * * *$ & $-.31 * * *$ & $.81 * * *$ & $.66 * * *$ & $-.29 * * *$ \\
\hline \multicolumn{9}{|c|}{$\begin{array}{l}\text { Note. } \mathrm{N}=453, * p<.05, * * p<.01, * * * p<.001 . \mathrm{GS}=\text { Genuine Self-Forgiveness, SP = Self- } \\
\text { Punitiveness, PS = Pseudo Self-Forgiveness, PA = Positive Affect, NA = Negative } \\
\text { Affect, } \mathrm{C}=\text { Closeness, PMB = Positive Maintenance Behaviors, NMB = Negative } \\
\text { Maintenance Behaviors, RS = Relationship Satisfaction. Correlations controlled for type } \\
\text { of infidelity, affair duration, relationship duration, and whether the partner knows of the } \\
\text { infidelity. }\end{array}$} \\
\hline
\end{tabular}


H1. The partial correlation table was used to answer hypothesis 1. As hypothesized, genuine self-forgiveness was significantly correlated with positive affect (r $=.23, p<.001)$, negative affect $(\mathrm{r}=.12, p=.01)$, closeness $(\mathrm{r}=.44, p<.001)$, positive maintenance behaviors $(\mathrm{r}=.48, p<.001)$, and relationship satisfaction $(\mathrm{r}=.42, p$ $<.001)$, but contrary to the hypothesis was not significantly correlated with negative maintenance behaviors $(\mathrm{r}=.02, p=.70)$. As hypothesized, self-punitiveness was significantly correlated with positive affect $(\mathrm{r}=.19, p=.01)$, negative affect $(\mathrm{r}=.54, p$ $<.001)$, closeness $(\mathrm{r}=.11, p=.01)$, positive maintenance behaviors $(\mathrm{r}=.12, p=.01)$, and negative maintenance behaviors $(\mathrm{r}=.46, p<.001)$, but contrary to the hypothesis was not significantly correlated with relationship satisfaction $(\mathrm{r}=.04, p=.39)$. As hypothesized, pseudo self-forgiveness was significantly correlated with negative affect ( $\mathrm{r}$ $=.47, p<.001)$, closeness $(\mathrm{r}=-.25, p<.001)$, positive maintenance behaviors $(\mathrm{r}=-.17, p$ $<.001)$, negative maintenance behaviors $(\mathrm{r}=.61, p<.001)$, and relationship satisfaction $(\mathrm{r}=-.39, p<.001)$, but contrary to the hypothesis was not significantly correlated with positive affect $(\mathrm{r}=.02, p=.72)$.

In summary, genuine self-forgiveness was significantly correlated with all study variables except negative maintenance behaviors, self-punitiveness was significantly correlated with all study variables except relationship satisfaction, and pseudo selfforgiveness was significantly correlated with all study variables except positive affect.

H2. The partial correlation matrix described above was used to create the path model in SPSS 21 AMOS statistical software to test the specified model (see Figure 1). The hypothesized model had poor fit to the data $\left(\chi^{2}(21)=893.55, p<.001, \mathrm{CFI}=.605\right.$, 
$\mathrm{TLI}=.322, \mathrm{RMSEA}=.30$, PClose $<.001)$ and was for this reason not fit for data interpretation.

Next, non-significant paths were removed to improve data interpretation of effect sizes and mediation effects. The four removed paths were genuine self-forgiveness to negative affect $(\beta=.03, p=.43)$, pseudo self-forgiveness to positive affect $(\beta=.05, p$ $=.33)$, self-punitiveness to positive affect $(\beta=.10, p=.06)$, and closeness to negative maintenance behaviors $(\beta=.05, p=.6)$. The model had poor fit to the data $\left(\chi^{2}(25)=\right.$ $904.40, p<.001, \mathrm{CFI}=.602, \mathrm{TLI}=.426, \mathrm{RMSEA}=.28$, PClose $<.001)$ and was for this reason not fit for data interpretation.

Next, omitted paths were added one at a time until acceptable model fit was reached. This was done to reduce type II error and avoid over-specification of the model. In total, seven omitted paths were retained to reach acceptable model fit. These paths were genuine self-forgiveness to closeness $(p<.001)$, genuine self-forgiveness to positive maintenance behaviors $(p<.001)$, pseudo self-forgiveness to negative maintenance behaviors $(p<.001)$, positive affect to positive maintenance behaviors $(p$ $<.001)$, positive affect to satisfaction $(p<.001)$, negative affect to negative maintenance behaviors $(p<.001)$, and closeness to satisfaction $(p<.001)$. With the inclusion of a path from closeness to satisfaction, the path from positive maintenance behaviors to satisfaction became insignificant $(\beta=-.04, p=.28)$ and was for this reason also removed from the model. The model had acceptable fit to the data with $\chi^{2}(19)=103.96, p<.001$, $\mathrm{CFI}=.962, \mathrm{TLI}=.927, \mathrm{RMSEA}=.099$, PClose $<.001$ (see Figure 2 for the model, standardized effect sizes, and significance levels) and was fit for interpretation to answer hypothesis 2 (i.e. that offender's positive and negative affect, relational closeness, and 


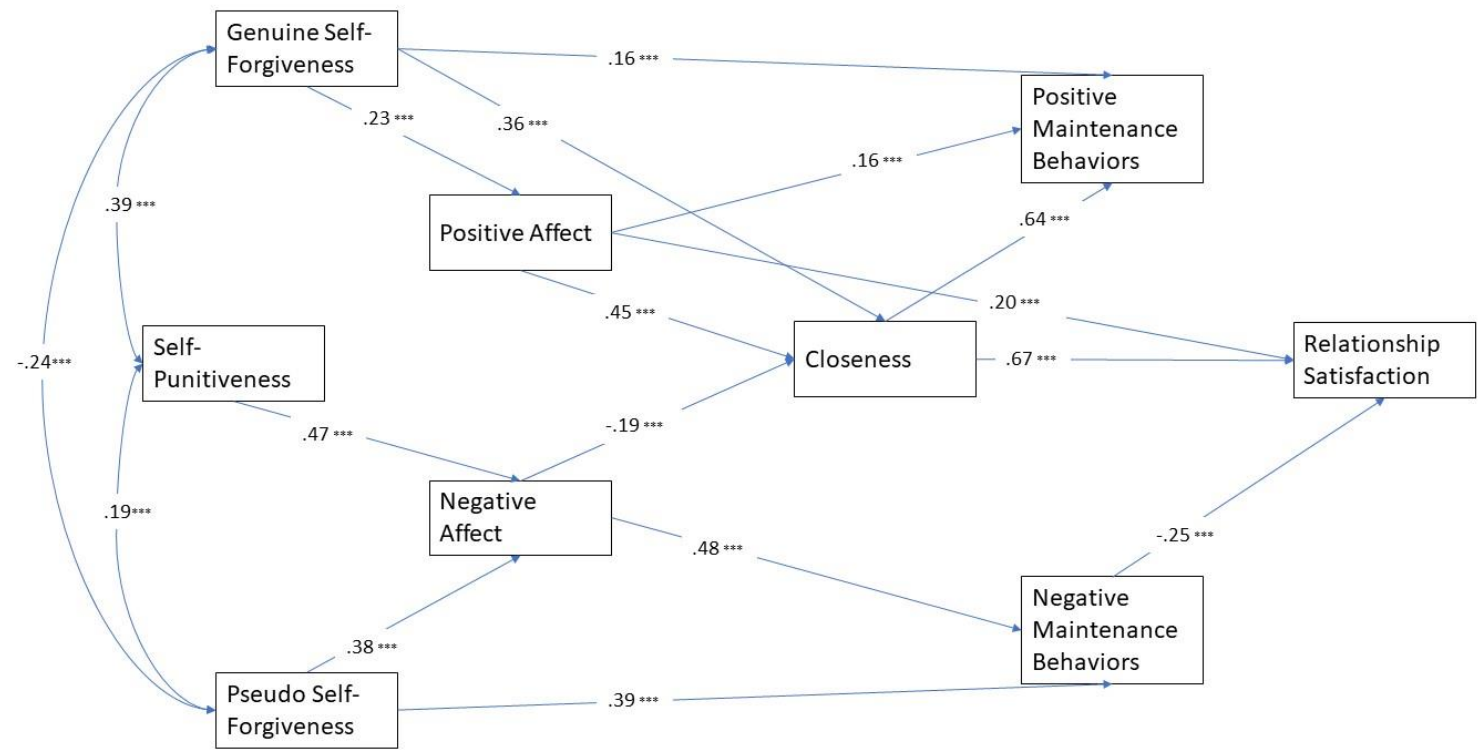

Figure 2. Path model analysis used to answer hypothesis 2 . $* * *$ indicates significance at the $p<.001$ level. 
positive and negative relational maintenance behaviors, fully mediate the relationship between self-forgiveness [genuine self-forgiveness, pseudo self-forgiveness, selfpunitiveness] and relationship satisfaction).

As hypothesized, genuine self-forgiveness had a significant indirect effect on relationship satisfaction $(\beta=.36, p<.01)$. As no direct path from genuine selfforgiveness to satisfaction had to be included in the model after testing for omitted paths, it is evident that positive affect and closeness fully mediated the relationship between genuine self-forgiveness and relationship satisfaction. Contrary to the hypothesis, negative affect, negative maintenance behaviors, and positive maintenance behaviors did not mediate the relationship between genuine self-forgiveness and relationship satisfaction.

As hypothesized, pseudo self-forgiveness had a significant inverse indirect effect on relationship satisfaction $(\beta=-.19, p=.01)$. As no direct path from pseudo selfforgiveness to satisfaction had to be included in the model after testing for omitted paths, it is evident that negative affect, closeness, and negative maintenance behaviors fully mediated the relationship between pseudo self-forgiveness and relationship satisfaction. Contrary to the hypothesis, positive affect and positive maintenance behaviors did not mediate the relationship between pseudo self-forgiveness and relationship satisfaction.

As hypothesized, self-punitiveness had a significant inverse indirect effect on relationship satisfaction $(\beta=-.12, p=.01)$. As no direct path from self-punitiveness to satisfaction had to be included in the model after testing for omitted paths, it is evident that negative affect, closeness, and negative maintenance behaviors fully mediated the relationship between self-punitiveness and relationship satisfaction. Contrary to the 
hypothesis, positive affect and positive maintenance behaviors did not mediate the relationship between self-punitiveness and relationship satisfaction.

In summary, positive affect and closeness fully mediated the relationship between genuine self-forgiveness and relationship satisfaction, while negative affect, positive maintenance behaviors, and negative maintenance behaviors did not. Negative affect, closeness, and negative maintenance behaviors fully mediated the inverse relationship between pseudo self-forgiveness and relationship satisfaction, and fully mediated the inverse relationship between self-punitiveness and relationship satisfaction. However, positive affect and positive maintenance behaviors did not mediate the relationship between pseudo self-forgiveness and relationship satisfaction, nor between selfpunitiveness and relationship satisfaction

H2a. To answer hypothesis 2a (i.e. that positive and negative affect fully mediate the relationship between self-forgiveness [genuine self-forgiveness, pseudo selfforgiveness, self-punitiveness] and closeness), the first half of the original hypothesized model was analyzed via path model analysis. The original hypothesized model had poor fit to the data $\left(\chi^{2}(4)=96.09, p<.001, \mathrm{CFI}=.864, \mathrm{TLI}=.491, \mathrm{RMSEA}=.23\right.$, PClose $<.001)$ and was not fit for data interpretation. Next, insignificant paths were removed from the model to improve data interpretation of effect sizes and mediation effects. The removed paths were genuine self-forgiveness to negative affect ( $\beta=.03, p=.43$ ), pseudo self-forgiveness to positive affect $(\beta=.05, p=.33)$, and self-punitiveness to positive affect $(\beta=.10, p=.05)$. The model had poor fit to the data $\left(\chi^{2}(7)=103.21, p<.001\right.$, CFI $=.858, \mathrm{TLI}=.696, \mathrm{RMSEA}=.17$, PClose $<.001)$ and was not fit for data interpretation. 
Next, omitted paths were added one at a time until acceptable model fit was reached. This was done to reduce type II error and avoid over-specification of the model. Only one path was added to reach acceptable model fit, which was a path from genuine self-forgiveness to closeness $(\mathrm{p}<.001)$. The model had acceptable fit to the data with $\chi^{2}(6)=19.08, p=.001, \mathrm{CFI}=.981, \mathrm{TLI}=.952, \mathrm{RMSEA}=.07$, PClose $=.15$ (see Figure 3 for the model, standardized effect sizes, and significance levels) and was fit for data interpretation to answer hypothesis $2 \mathrm{a}$.

As hypothesized, genuine self-forgiveness was significantly related to positive affect $(\beta=.23, p<.001)$, but contrary to the hypothesis was not significantly related to negative affect. Genuine self-forgiveness had a significant indirect effect on closeness through positive affect $(\beta=.11, p=.01)$, a significant direct effect on closeness $(\beta=.36$, $p<.01)$, and a significant total effect on closeness $(\beta=.46, p=.01)$. Thus, positive affect partially mediated the relationship between genuine self-forgiveness and closeness $(23.91 \%)$.

As hypothesized, pseudo self-forgiveness was significantly related to negative affect $(\beta=.38, p<.001)$, but contrary to the hypothesis was not significantly related to positive affect. Pseudo self-forgiveness had a significant inverse indirect effect on closeness through negative affect $(\beta=-.07, p=.01)$. As no significant direct path from pseudo self-forgiveness to closeness had to be included in the model after testing for omitted paths, it is evident that negative affect fully mediated the relationship between pseudo self-forgiveness and closeness.

As hypothesized self-punitiveness was significantly related to negative affect ( $\beta$ $=.47, p<.001)$, but contrary to the hypothesis was not significantly related to positive 


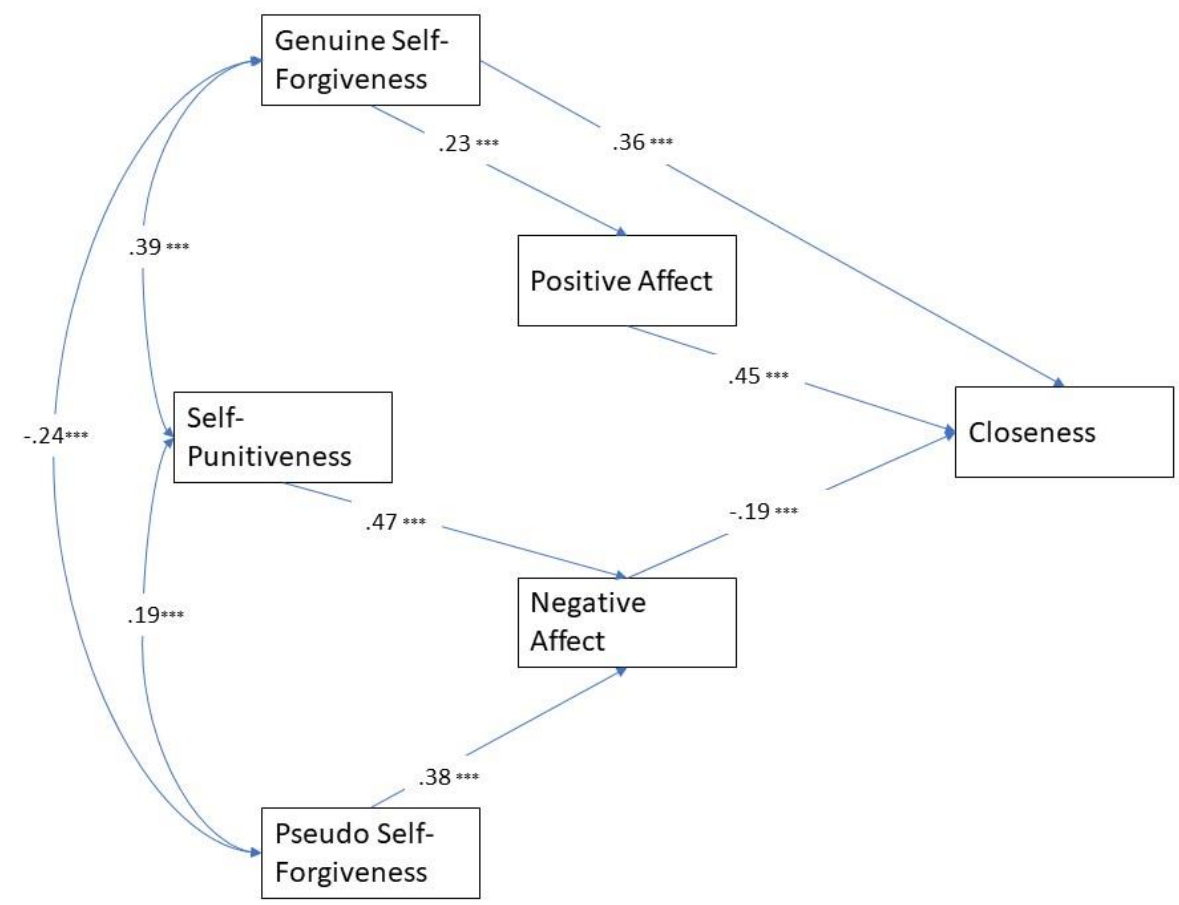

Figure 3. Path model analysis used to answer hypothesis $2 \mathrm{a}$. $* * *$ indicates significance at the $p<.001$ level. 
affect. Self-punitiveness had a significant inverse indirect effect on closeness through negative affect $(\beta=-.09, p<.01)$. As no significant direct path from self-punitiveness to closeness had to be included in the model after testing for omitted paths, it is evident that negative affect fully mediated the relationship between self-punitiveness and closeness.

In summary, positive affect partially mediated the relationship between genuine self-forgiveness and closeness, while negative affect did not mediate that relationship. Negative affect fully mediated the inverse relationship between pseudo self-forgiveness and closeness, and the inverse relationship between self-punitiveness and closeness, while positive affect did not mediate these relationships.

H2b. To answer hypothesis $2 \mathrm{~b}$ (i.e. that positive and negative maintenance behaviors fully mediate the relationship between closeness and relationship satisfaction), the second half of the original hypothesized model was analyzed via path model analysis. The original hypothesized model had poor fit to the data $\left(\chi^{2}(2)=256.58, p<.001\right.$, CFI $=.746, \mathrm{TLI}=.239, \mathrm{RMSEA}=.53$, PClose $<.001)$ and was not fit for data interpretation. Next, non-significant paths were removed from the model to improve data interpretation of effect sizes and potential mediation effects. Only one path was removed, which was from closeness to negative maintenance behaviors $(\beta=-.09, p=.06)$. The model had poor fit to the data $\left(\chi^{2}(3)=260.26, p<.001, \mathrm{CFI}=.744, \mathrm{TLI}=.487, \mathrm{RMSEA}=.436\right.$, PClose $<.001)$ and was not fit for data interpretation.

Next, omitted paths were tested to see if any would need to be included in the model. As expected based on the full model analysis explained above, the path from closeness to relationship satisfaction was significant $(p<.001)$ and thus retained in the model. With the inclusion of a path from closeness to satisfaction, the path from positive 
maintenance behaviors to satisfaction became insignificant $(\beta=.03, p=.55)$ and was for this reason removed from the model. The model had excellent fit to the data with $\chi^{2}(3)=$ $4.31, p=.23, \mathrm{CFI}=.999, \mathrm{TLI}=.997, \mathrm{RMSEA}=.03$, PClose $=.62$. (see Figure 4 for the model, standardized effect sizes, and significance levels) and was fit for data interpretation to answer hypothesis $2 \mathrm{~b}$.

As hypothesized, closeness had a significant effect on positive maintenance behaviors $(\beta=.79, p<.001)$, but contrary to the hypothesis was not significantly related to negative maintenance behaviors. While negative maintenance behaviors did have a significant inverse effect on relationship satisfaction $(\beta=-.22, p<.001)$, positive maintenance behaviors were not significantly related to relationship satisfaction. Thus, contrary to the hypothesis, the relationship between closeness and relationship satisfaction was neither mediated by positive maintenance behaviors nor by negative maintenance behaviors.

In summary, closeness was significantly related to positive maintenance behaviors, but not to negative maintenance behaviors. Closeness and negative maintenance behaviors were significantly related to relationship satisfaction. Neither positive maintenance behaviors nor negative maintenance behaviors mediated the relationship between closeness and relationship satisfaction, likely because the correlation between closeness and satisfaction was so high that there was little variance to be partitioned.

\section{Supplementary Analyses}

Because of the high correlation between closeness and relationship satisfaction in this study, closeness was removed from the model and the model was retested with the 


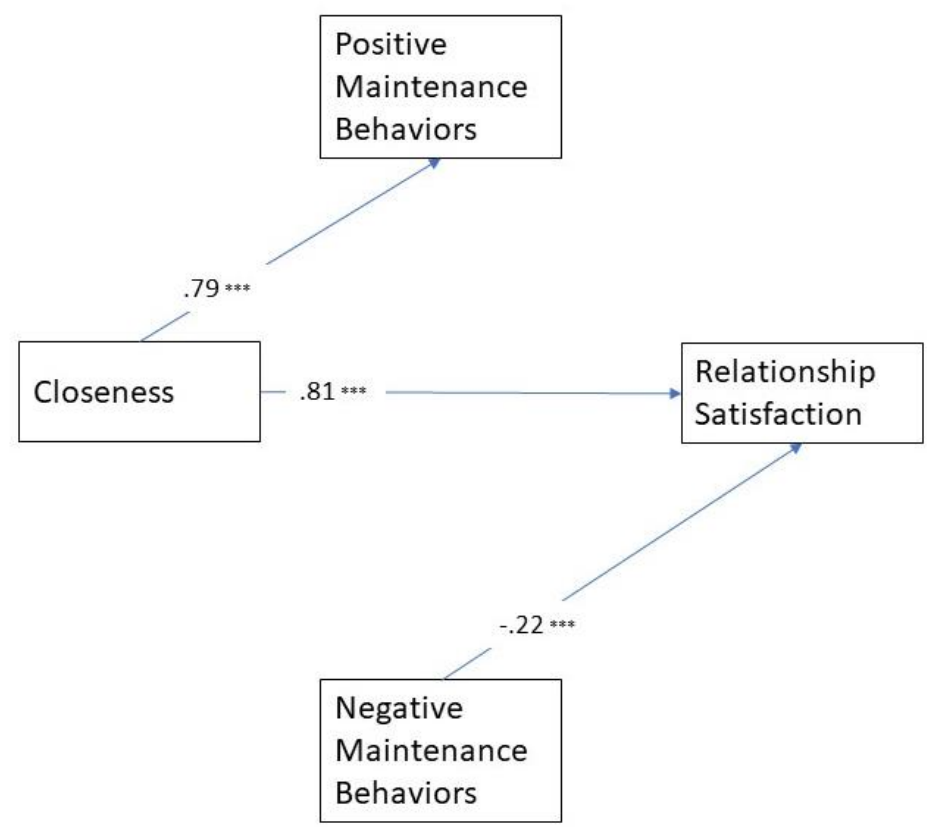

Figure 4. Path model analysis used to answer hypothesis $2 \mathrm{~b}$. *** indicates significance at the $p<.001$ level. 
absence of closeness. This aided in evaluating whether the findings explained above could be replicated in the absence of closeness, which may have influenced the above explained findings given the high correlation between closeness and relationship satisfaction in this sample. The model (with closeness removed) had poor fit to the data $\chi^{2}(16)=259.51, p<.001, \mathrm{CFI}=.838, \mathrm{TLI}=.717, \mathrm{RMSEA}=.183$, PClose $\left.<.001\right)$ and was not fit for data interpretation.

Next, omitted paths were added one at a time until acceptable model fit was reached. This was done to reduce type II error and avoid over-specification of the model. In total, four omitted paths were retained to reach acceptable model fit. The retained paths were genuine self-forgiveness to relationship satisfaction $(p<.001)$, selfpunitiveness to negative maintenance behaviors $(p<.001)$, positive maintenance behaviors to relationship satisfaction $(p<.001)$, and negative affect to relationship satisfaction $(p<.001)$. The model had acceptable fit to the data with $\chi^{2}(12)=60.47, p$ $<.001, \mathrm{CFI}=.968, \mathrm{TLI}=.925, \mathrm{RMSEA}<.01$, PClose $=.001$ (see Figure 5 for the model, standardized effect sizes, and significance levels) and was fit for data interpretation.

Genuine self-forgiveness had a significant total effect on relationship satisfaction $(\beta=.45, p<.01)$, a significant indirect effect on relationship satisfaction $(\beta=.25, p$ $=.01)$, and a significant direct effect on relationship satisfaction $(\beta=.20, p<.01)$. Positive affect and positive maintenance behaviors mediated 55.56\% of the relationship between genuine self-forgiveness and relationship satisfaction.

Pseudo self-forgiveness had a significant inverse indirect effect on relationship satisfaction $(\beta=-.17, p<.01)$. As no direct path from pseudo self-forgiveness to 


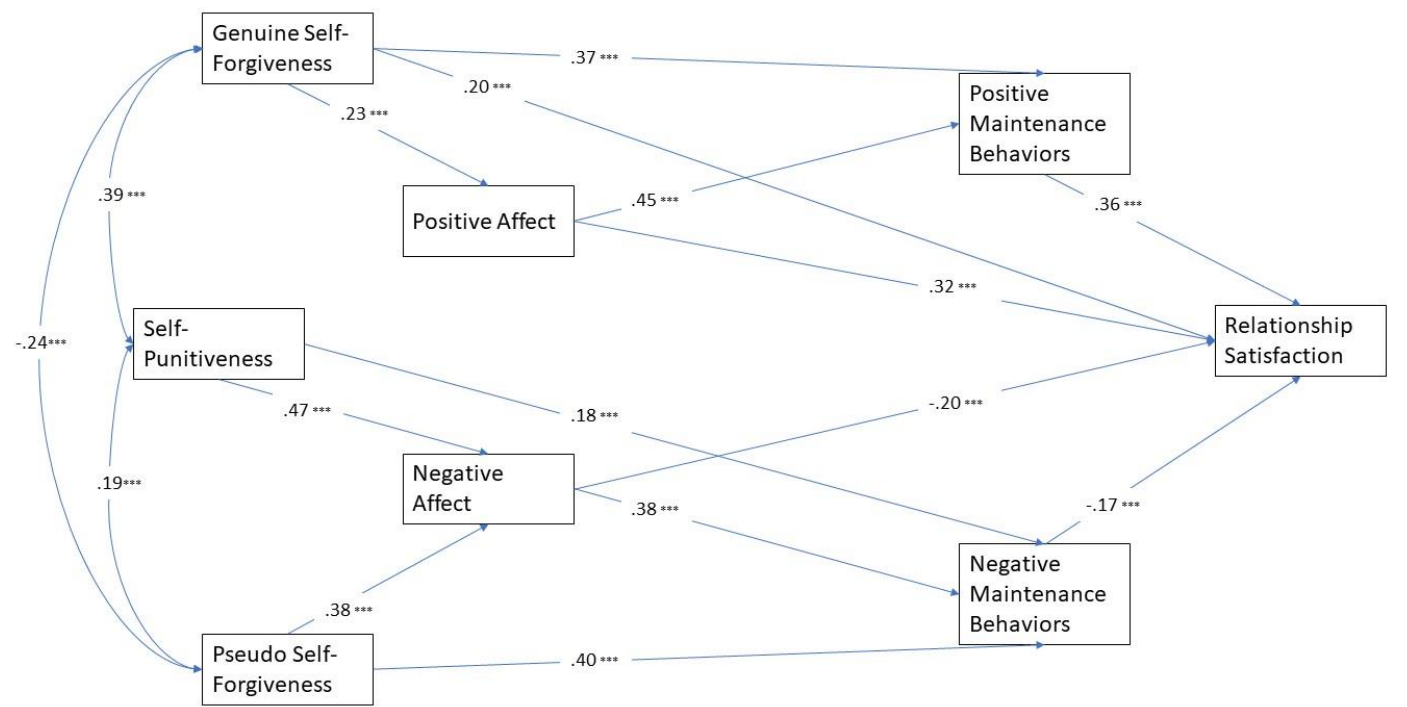

Figure 5. Path model analysis used for the supplementary analyses. *** indicates significance at the $p<.001$ level. 
satisfaction had to be included in the model after testing for omitted paths, it is evident that negative affect and negative maintenance behaviors fully mediated the relationship between pseudo self-forgiveness and relationship satisfaction. Self-punitiveness had a significant inverse indirect effect on relationship satisfaction $(\beta=-.15, p<.01)$. As no direct path from self-punitiveness to satisfaction had to be included in the model after testing for omitted paths, it is evident that negative affect and negative maintenance behaviors fully mediated the relationship between self-punitiveness and relationship satisfaction.

Negative affect had a significant inverse total effect $(\beta=-.26, p<.01)$, indirect effect $(\beta=-.06, p<.01)$, and direct effect on relationship satisfaction $(\beta=-.20, p<.01)$, indicating that negative maintenance behaviors partially mediated (23.08\%) the relationship between negative affect and relationship satisfaction. Positive affect had a significant total effect $(\beta=.48, p=.01)$, indirect effect $(\beta=.16, p=.02)$, and direct effect on relationship satisfaction $(\beta=.32, p<.01)$, indicating that positive maintenance behaviors partially mediated (33.33\%) the relationship between positive affect and relationship satisfaction.

In summary, positive affect and positive maintenance behaviors partially mediated the relationship between genuine self-forgiveness and relationship satisfaction. Negative affect and negative maintenance behaviors fully mediated the inverse relationship between pseudo self-forgiveness and relationship satisfaction, and between self-punitiveness and relationship satisfaction. Positive maintenance behaviors partially mediated the relationship between positive affect and relationship satisfaction. Negative 
maintenance behaviors partially mediated the relationship between negative affect and relationship satisfaction. 


\section{CHAPTER IV: DISCUSSION}

The purpose of this study was to examine how genuine self-forgiveness, pseudo self-forgiveness, and self-punitiveness impact relationship satisfaction post-infidelity for individuals who are still with the same partner they betrayed within the last 2 years. Prior to this study, researchers have found that offenders' self-forgiveness after an interpersonal offense is associated with intrapersonal and interpersonal healing, as well as with increased relationship satisfaction (Hall \& Fincham, 2005; Pelucchi et al., 2013; Pelucchi et al., 2015). However, the pathway between self-forgiveness and relationship satisfaction has been unclear and the current study begins to understand those linkages. Additionally, before this paper there was no published study regarding the effects of selfforgiveness post-infidelity. With support of affect theory of social exchange, it was hypothesized that positive and negative affect, closeness to one's partner, and positive and negative maintenance behaviors fully mediate the relationship between selfforgiveness and relationship satisfaction post-infidelity. This hypothesis was partially supported by the research findings.

As expected, genuine self-forgiveness was positively associated with positive affect, relational closeness, positive maintenance behaviors, and relationship satisfaction. This finding is consistent with the argument of Hall and Fincham (2005) and Pelucchi et al. (2013) regarding genuine self-forgiveness bringing about intrapersonal and interpersonal healing. In this study, positive affect and relational closeness fully mediated the relationship between genuine self-forgiveness and relationship satisfaction. When 
closeness was removed from the model (because of the high correlation between closeness and relationship satisfaction), positive affect and positive maintenance behaviors partially mediated the relationship between genuine self-forgiveness and relationship satisfaction. Study findings suggest that genuine self-forgiveness primarily operated by improving one's positive emotional experiences and improving positive behaviors and attitudes toward one's partner. Woodyatt and Wenzel (2013) argued that genuine self-forgiveness aids individuals in alleviating their guilt, shame, and selfresentment (i.e. negative emotions), but current findings suggest that genuine selfforgiveness primarily aids in improving one's positive emotional experiences, but not in alleviating one's negative emotions. In this study, the association between selfforgiveness and negative emotions was better explained by pseudo self-forgiveness and self-punitiveness. However, an alternative explanation could be that genuine selfforgiveness may be a process that follows self-punitiveness instead of a separate response to an interpersonal offense, thus explaining the lack of connection between genuine selfforgiveness and decreased negative affect and decreased negative maintenance behaviors in the current study.

Self-punitiveness had the strongest association with negative affect in the current study, indicative of the overwhelming nature of self-punishing thoughts and emotions (e.g. guilt, shame, self-contempt) that self-punitive individuals experience post-infidelity. As expected, self-punitiveness was positively related to negative affect and negative maintenance behaviors, and inversely related to relational closeness. Additionally, the inverse relationship between self-punitiveness and relationship satisfaction was fully mediated by negative affect, closeness, and negative maintenance behaviors. Similarly, 
when closeness was removed from the analyses, the inverse relationship between selfpunitiveness and relationship satisfaction was still fully mediated by negative affect and negative maintenance behaviors. This goes hand in hand with previous theoretical and empirical findings about the negative intrapersonal effects (e.g. Van Bunderen \& Bastian, 2014; Witvliet et al., 2011; Woodyat et al., 2012) and interpersonal effects (Pelucchi et al., 2013; Witvliet et al., 2011) of self-punitiveness.

As with self-punitiveness, pseudo self-forgiveness was positively associated with negative affect and negative maintenance behaviors in this study, and negatively associated with closeness and relationship satisfaction. Additionally, the inverse relationship between pseudo self-forgiveness and relationship satisfaction was fully mediated by negative affect, closeness, and negative maintenance behaviors. Even with closeness removed from the model, negative affect and negative maintenance behaviors fully mediated the relationship between pseudo self-forgiveness and relationship satisfaction. The association between pseudo self-forgiveness and negative intrapersonal and interpersonal variables is likely due to individuals exhibiting pseudo self-forgiveness fully or partially blaming their partner for their own offense/infidelity (Woodyatt \& Wenzel, 2013). Having such a negative view about their committed romantic partner while still being in a relationship with that partner likely increases negative emotional experiences while also negatively impacting interpersonal behaviors and emotions (Pelucchi et al., 2017).

Contrary to expectations, positive affect only partially mediated the relationship between genuine self-forgiveness and closeness, while negative affect fully mediated the relationship between pseudo self-forgiveness and closeness, and self-punitiveness and 
closeness. Genuine self-forgiveness likely had a significant direct effect on closeness (in addition to an indirect effect as was expected) based on genuine self-forgiveness not only changing attitudes toward oneself, but simultaneously also attitudes, emotions, and behaviors toward one's victim (Fisher and Exline, 2010). In fact, researchers have found that individuals participating in genuine self-forgiveness do not want to recommit the same offense again, thus increasing their commitment toward their partner (Hall \& Fincham, 2005; Pelucchi et al., 2013, Witvliet et al., 2011) and likely also their closeness toward their partner. On the other hand, self-punitiveness and pseudo self-forgiveness did not directly influence relationship closeness, but as expected only indirectly. The indirect relationship is likely explained by individuals participating in pseudo self-forgiveness and self-punitiveness at least partially attributing their negative affect to their relationship/partner (Forgas et al., 1994; Lawler, 2001) through emotional spillover (Berscheid \& Ammazzalorso, 2001).

Contrary to expectations, positive and negative maintenance behaviors did not mediate the relationship between closeness and relationship satisfaction in this study. One explanation for this finding could be that maintenance behaviors depend on how individuals feel emotionally (i.e. individuals who feel well engage in more positive behaviors, and individuals who feel unwell engage in more negative behaviors) while also being influenced by how individuals feel about the relationship in general. Thus, instead of mediating the relationship between closeness and relationship satisfaction, maintenance behaviors may instead be the product of how one feels personally and how one feels about the relationship/partner. However, when considering the high correlation between closeness and relationship satisfaction in this study $(\mathrm{r}=.81)$, the more likely 
explanation for the current study findings is that there was little variance to be partitioned between closeness and relationship satisfaction.

\section{Limitations and Future Directions}

When interpreting the results of the current study, the study limitations need to be considered. First, there was a strong correlation between closeness and relationship satisfaction in this study, which made it difficult to fully understand the relationship between closeness, maintenance behaviors, and relationship satisfaction. In most studies to date, the correlation between closeness and relationship satisfaction has ranged between about .5 - .7 for partners in romantic relationships (e.g. Aron, Aron, \& Smollan, 1992; Dibble et al., 2011). Using the available demographic variables in this study as control variables (i.e. type of relationship during affair, current relationship status, gender, ethnicity, sexual orientation, age) in addition to the already incorporated control variables did not change the correlation between closeness and relationship satisfaction in the current sample. The URCS was specifically chosen for this study given that the other two prominent measures of relational closeness did not quite fit the study purposes. To be specific, the Relationship Closeness Inventory (RCI) developed by Berscheid et al. (1989) is a multidimensional measure (note: this study sought a unidimensional measure) of relationship closeness and mainly focuses on observable behaviors of closeness. The Inclusion of Other in the Self Scale (IOS) developed by Aron et al. (1992) is essentially a one item measure (note: this limits reliability and predictive validity) where participants are asked to circle one of seven Venn-like diagrams that most closely represents their relationship with their partner. Future research should continue using the URCS and continue evaluating its correlation with relationship satisfaction to investigate whether the 
high correlation in this study simply happened by chance, or if there are measurement issues that need to be addressed.

A second limitation is the generalizability of the study findings. In addition to generalizability limitations inherent to participant inclusion criteria (i.e. individuals who participated in infidelity within the past 2 years, were above the age of 18 when they participated in infidelity, and are still with the partner they betrayed), generalizability limitations also result from only individuals with access to the internet and an MTurk account having been able to participate. Future researchers should also evaluate the study findings separately for individuals from various cultural backgrounds (e.g. SES status, religious background, sexual orientation), because culture influences how individuals process stressful events (Hobfoll, 2001).

Third, the study was correlational in nature. Thus, it is impossible to determine cause and effect relationships. However, experimental designs regarding infidelity would be unethical, and experimental vignettes to simulate (in this case) infidelity are generally viewed as inferior to collecting real life data. For example, Hughes and Huby (2002) found that individuals responding to experimental vignettes do not consider all the complexities that go into real life situations, making it difficult to generalize from experimental vignette designs. An improvement upon the current study would be to implement a longitudinal design to evaluate the temporal relationship between the here used study variables. This would allow researchers to move closer toward understanding cause and effect relationships between self-forgiveness and interpersonal and intrapersonal variables post-infidelity. 


\section{Conclusion}

Despite the limitations of this study, the findings suggest that infidelity related self-forgiveness significantly impacts individuals' intrapersonal emotional experiences and interpersonal behaviors and feelings toward one's partner/relationship. These findings demonstrate that self-forgiveness needs to be given more attention in infidelity research, and that perpetrators' experiences post-infidelity also need to be given more attention. Doing so will aid in gaining a better understanding regarding couples' healing processes post-infidelity, and gaining better understanding regarding not only victims' healing processes but also perpetrators' healing processes. From a practical standpoint, the study findings may aid clinicians working with couples or individuals who have participated in infidelity in understanding that genuine self-forgiveness appears to be essential in rebuilding positive affective experiences and satisfying relationships for those who remain with the partner they betrayed. At the same time, clinicians can also be aware of the associations self-punitiveness and pseudo self-forgiveness have with increased negative affect and negative maintenance behaviors, and decreased closeness and relationship satisfaction. In general, clinicians should not only focus on aiding infidelity victims in forgiving perpetrators, but also aid perpetrators in participating in a genuine self-forgiveness process. 


\section{REFERENCES}

Amato, P. R., \& Previti, D. (2003). People's reasons for divorcing: Gender, social class, the life course, and adjustment. Journal of Family Issues, 24, 602-626.

Antin, J., \& Shaw, A. (2012). Social desirability bias and self-reports of motivation: a study of amazon mechanical turk in the US and India. In Proceedings of the SIGCHI Conference on Human Factors in Computing Systems (pp. 2925-2934). New York, NY: ACM.

Armitage, C. J., \& Harris, P. R. (2006). The influence of adult attachment on symptom reporting: Testing a mediational model in a sample of the general population. Psychology and Health, 21, 351-366.

Aron, A., Aron, E. N., \& Smollan, D. (1992). Inclusion of other in the self scale and the structure of interpersonal closeness. Journal of Personality and Social Psychology, 63, 596-612.

Atkins, D., Baucom, D., \& Jacobson, N. (2001). Understanding infidelity: Correlates in a national random sample. Journal of Family Psychology, 15, 735-749.

Baumeister, M., Kwang, T., \& Gosling, S. D. (2011). Amazon's Mechanical Turk a new source of inexpensive, yet high-quality, data? Perspectives on Psychological Science, 6, 3-5.

Baumeister, R. F., \& Leary, M. R. (1995). The need to belong: desire for interpersonal attachments as a fundamental human motivation. Psychological Bulletin, 117, 497-529. 
Berscheid, E., \& Ammazzalorso, H. (2001). Emotional experience in close relationships. In G. J. Fletcher \& M. S. Clark (Eds.), Blackwell handbook of social psychology: Interpersonal processes. Oxford, United Kingdom: John Wiley \& Sons.

Berscheid, E., Snyder, M., \& Omoto, A. M. (1989). The Relationship Closeness Inventory: Assessing the closeness of interpersonal relationships. Journal of Personality and Social Psychology, 57, 792-807. Blow, A. J., \& Hartnett, K. (2005). Infidelity in committed relationships ii: A substantive review. Journal of Marital and Family Therapy, 31, 217-233.

Burke, A., \& Haslam, N. (2001). Relations between personality and depressive symptoms: A multimeasure study of dependency, autonomy, and related constructs. Journal of Clinical Psychology, 57, 953-961. Buss, D. M. (2000). The dangerous passion. New York, NY: The Free Press.

Byers, E. S. (2005). Relationship satisfaction and sexual satisfaction: A longitudinal study of individuals in long-term relationships. Journal of Sex Research, 42, 113 118.

Canary, D. J., \& Stafford, L. (1994). Maintaining relationships through strategic and routine interaction. In D. J. Canary \& L. Stafford (Eds.), Communication and Relational Maintenance (pp. 3-22). San Diego, CA: Academic Press.

Canary, D.J., \& Stafford, L. (1992). Relational maintenance strategies and equity in marriage. Dainton, M., \& Gross, J. (2008). The use of negative behaviors to maintain relationships. Communication Monographs, 59, 243-267. 
Canary, D. J., Stafford, L., \& Semic, B. A. (2002). A panel study of the associations between maintenance strategies and relational characteristics. Journal of Marriage and Family, 64, 395-406.

Casler, K., Bickel, L., \& Hackett, E. (2013). Separate but equal? A comparison of participants and data gathered via Amazon's MTurk, social media, and face-toface behavioral testing. Computers in Human Behavior, 29, 2156-2160.

Coccia, C., \& Darling, C. A. (2016). Having the time of their life: College student stress, dating and satisfaction with life. Stress and Health, 32, 28-35.

Cohen, A. (2013). The Association Between Self-Forgiveness and Marital Satisfaction (Doctoral dissertation). Retrieved from ProQuest Dissertations and Theses. (Accession Order No. AAI3515246)

Cornish, M. A., \& Wade, N. G. (2015). Working through past wrongdoing: Examination of a self-forgiveness counseling intervention. Journal of Counseling Psychology, 62, 521-528.

Crawford, J. R., \& Henry, J. D. (2004). The Positive and Negative Affect Schedule (PANAS): Construct validity, measurement properties and normative data in a large non-clinical sample. British Journal of Clinical Psychology, 43, 245-265.

Dainton, M., \& Gross, J. (2008). The use of negative behaviors to maintain relationships. Communication Research Reports, 25, 179-191.

da Silva, S. P., Witvliet, C., \& Riek, B. (2017). Self-forgiveness and forgiveness-seeking in response to rumination: Cardiac and emotional responses of transgressors. The Journal of Positive Psychology, 12, 362-372. 
Dibble, J. L., Levine, T. R., \& Park, H. S. (2012). The Unidimensional Relationship Closeness Scale (URCS): reliability and validity evidence for a new measure of relationship closeness. Psychological Assessment, 24, 565-572.

Ehlers, A., Mezey, G., \& Clark, D. M. (2007). Intrusive memories in perpetrators of violent crime: Emotions and cognitions. Journal of Consulting and Clinical Psychology, 75, 134-144.

Fernandez, A. M., Vera-Villarroel, P., Sierra, J. C., \& Zubeidat, I. (2007). Distress in response to emotional and sexual infidelity: Evidence of evolved gender differences in Spanish students. The Journal of Psychology, 141, 17-24.

Field, A. (2009). Discovering statistics using IBM SPSS statistics. Thousand Oaks, CA: Sage Publications Inc.

Fisher, A. D., Corona, G., Bandini, E., Mannucci, E., Lotti, F., Boddi, V., ... \& Maggi, M. (2009). Psychobiological correlates of extramarital affairs and differences between stable and occasional infidelity among men with sexual dysfunctions. The Journal of Sexual Medicine, 6, 866-875.

Fisher, M. L., \& Exline, J. J. (2006). Self-forgiveness versus excusing: The roles of remorse, effort, and acceptance of responsibility. Self and Identity, 5, 127-146.

Flett, G. L., Goldstein, A. L., Hewitt, P. L., \& Wekerle, C. (2012). Predictors of deliberate self-harm behavior among emerging adolescents: An initial test of a self-punitiveness model. Current Psychology, 31, 49-64.

Ford, J. B. (2017). Amazon's Mechanical Turk: A comment. Journal of Advertising, 46, 156-158. 
Forgas, J. P., Levinger, G., \& Moylan, S. J. (1994). Feeling good and feeling close: Affective influences on the perception of intimate relationships. Personal Relationships, 1, 165-184.

Funk, J. L., \& Rogge, R. D. (2007). Testing the ruler with item response theory: increasing precision of measurement for relationship satisfaction with the Couples Satisfaction Index. Journal of Family Psychology, 21, 572-583.

Gordon, K.C., \& Baucom, D.H. (1999). A multitheoretical intervention for promoting recovery from extramarital affairs. Clinical Psychology: Science and Practice, 6, 382-399.

Gordon, K. C., Baucom, D. H., \& Snyder, D. K. (2004). An integrative intervention for promoting recovery from extramarital affairs. Journal of Marital and Family Therapy, 30, 213-231.

Gravetter, F., \& Wallnau, L. (2014). Essentials of statistics for the behavioral sciences. Belmont, CA: Wadsworth

Hall, J. H., \& Fincham, F. D. (2005). Self-forgiveness: The stepchild of forgiveness research. Journal of Social and Clinical Psychology, 24, 621-637.

Hauser, D. J., \& Schwarz, N. (2016). Attentive Turkers: MTurk participants perform better on online attention checks than do subject pool participants. Behavior Research Methods, 48, 400-407.

Hesse, C., Pauley, P. M., \& Frye-Cox, N. E. (2015). Alexithymia and marital quality: The mediating role of relationship maintenance behaviors. Western Journal of Communication, 79, 45-72. 
Hobfoll, S. E. (2001). The influence of culture, community, and the nested-self in the stress process: advancing conservation of resources theory. Applied psychology, 50, 337-421.

Hughes, R., \& Huby, M. (2002). The application of vignettes in social and nursing research. Journal of Advanced Nursing, 37, 382-386.

Huston, T. L., \& Vangelisti, A. L. (1991). Socioemotional behavior and satisfaction in marital relationships: A longitudinal study. Journal of Personality and Social Psychology, 61, 721-733.

Ingersoll-Dayton, B., Torges, C., \& Krause, N. (2010). Unforgiveness, rumination, and depressive symptoms among older adults. Aging \& Mental Health, 14, 439-449.

IJzerman, H., Blanken, I., Brandt, M. J., Oerlemans, J. M., Van den Hoogenhof, M. M., Franken, S. J., \& Oerlemans, M. W. (2014). Sex differences in distress from infidelity in early adulthood and in later life. Social Psychology, 45, 202-208.

Johnson, M. D., Cohan, C. L., Davila, J., Lawrence, E., Rogge, R. D., Karney, B. R., ... \& Bradbury, T. N. (2005). Problem-solving skills and affective expressions as predictors of change in marital satisfaction. Journal of Consulting and Clinical Psychology, 73, 15-27.

Joinson, A. (1999). Social desirability, anonymity, and Internet-based questionnaires. Behavior Research Methods, Instruments, \& Computers, 31, 433438.

Kaye-Tzadok, A., \& Davidson-Arad, B. (2016). Posttraumatic growth among women survivors of childhood sexual abuse: Its relation to cognitive strategies, 
posttraumatic symptoms, and resilience. Psychological Trauma: Theory, Research, Practice, and Policy, 8, 550-558.

Kees, J., Berry, C., Burton, S., \& Sheehan, K. (2017). Reply to “Amazon's Mechanical Turk: A comment”. Journal of Advertising, 46, 159-162.

Kelley, H. H., Berscheid, E., Christensen, A., Harvey, J. H., Huston, T. L., Levinger, G., ... \& Peterson, D. R. (1983). Analyzing close relationships. In H. H. Kelley, E. Berscheid, A Christensen, J. H. Harvey, T. L. Huston, G. Levinger, ... \& D. R. Peterson (Eds.), Close relationships (pp. 20-67). New York, NY: W. H. Freeman and Company.

Kiecolt-Glaser, J. K., Bane, C., Glaser, R., \& Malarkey, W. B. (2003). Love, marriage, and divorce: newlyweds' stress hormones foreshadow relationship changes. Journal of Consulting and Clinical Psychology, 71, 176-188.

Kim, L. M., Johnson, J. L., \& Ripley, J. (2011). A “perfect” storm: Perfectionism, forgiveness, and marital satisfaction. Individual Differences Research, 9, 199209.

Lawler, E. J. (2001). An affect theory of social exchange. American Journal of Sociology, 107, 321-352.

Lawler, E. J., \& Yoon, J. (1996). Commitment in exchange relations: Test of a theory of relational cohesion. American Sociological Review, 61, 89-108.

Lawson, A., \& Samson, C. (1988). Age, gender and adultery. British Journal of Sociology, 39, 409-440. 
Ledbetter, A. M. (2009). Family communication patterns and relational maintenance behavior: Direct and mediated associations with friendship closeness. Human Communication Research, 35, 130-147.

McConnell, J. M. (2015). A conceptual-theoretical-empirical framework for selfforgiveness: Implications for research and practice. Basic and Applied Social Psychology, 37, 143-164.

McNulty, J. K., \& Russell, V. M. (2010). When "negative” behaviors are positive: A contextual analysis of the long-term effects of problem-solving behaviors on changes in relationship satisfaction. Journal of Personality and Social Psychology, 98, 587-604.

Molm, L. D. (1994). Dependence and risk: Transforming the structure of social exchange. Social Psychology Quarterly, 163-176.

National Fatherhood Initiative. (2005). With this ring ... A national survey on marriage in America. Gaithersburg, MD: Author

Negash, S., Cui, M., Fincham, F. D., \& Pasley, K. (2014). Extradyadic involvement and relationship dissolution in heterosexual women university students. Archives of Sexual Behavior, 43, 531-539.

O’Rourke, N., \& Hatcher, L. (2013). A step-by-step approach to using SAS for factor analysis and structural equation modeling. Cary, NC: SAS Institute Inc.

Pelucchi, S., Paleari, F. G., Regalia, C., \& Fincham, F. D. (2013). Self-forgiveness in romantic relationships: It matters to both of us. Journal of Family Psychology, 27, 541-549. 
Pelucchi, S., Paleari, F. G., Regalia, C., \& Fincham, F. D. (2015). Self-forgiveness in romantic relationships: 2. Impact on interpersonal forgiveness. Family Science, 6, 181-190.

Pelucchi, Regalia, Paleari, \& Fincham (2017). Self-Forgiveness within couple transgressions. In L. Woodyatt, E. L. Worthington, M. Wenzel, \& B. J. Griffin (Eds.) Handbook of the psychology of self-forgiveness (pp. 43-58). Cham, Switzerland: Springer.

Riek, B. M., Luna, L. M. R., \& Schnabelrauch, C. A. (2014). Transgressors' guilt and shame: A longitudinal examination of forgiveness seeking. Journal of Social and Personal Relationships, 31, 751-772.

Ruffieux, M., Nussbeck, F. W., \& Bodenmann, G. (2014). Long-Term Prediction of Relationship Satisfaction and Stability by Stress, Coping, Communication, and Well-Being. Journal of Divorce \& Remarriage, 55, 485-501.

Scherer, M., Worthington Jr, E. L., Hook, J. N., \& Campana, K. L. (2011). Forgiveness and the bottle: Promoting self-forgiveness in individuals who abuse alcohol. Journal of Addictive Diseases, 30, 382-395.

Squires, E. C., Sztainert, T., Gillen, N. R., Caouette, J., \& Wohl, M. J. (2012). The problem with self-forgiveness: Forgiving the self deters readiness to change among gamblers. Journal of Gambling Studies, 28, 337-350.

Stafford, L., \& Canary, D.J. (1991). Maintenance strategies and romantic relationship type, gender, and relational characteristics. Journal of Social and Personal Relationships, 8, 217-242. 
Thompson, L. Y., Snyder, C. R., Hoffman, L., Michael, S. T., Rasmussen, H. N., Billings, L. S., ... \& Roberts, D. E. (2005). Dispositional forgiveness of self, others, and situations. Journal of Personality, 73, 313-360.

Van Bunderen, L., \& Bastian, B. (2014). "I have paid my dues": When physical pain reduces interpersonal justice motivations. Motivation and Emotion, 38, 540-546.

Watson, D., Clark, L. A., \& Tellegen, A. (1988). Development and validation of brief measures of positive and negative affect: the PANAS scales. Journal of Personality and Social Psychology, 54, 1063-1070.

Weigel, D. J., \& Ballard-Reisch, D. S. (2001). The impact of relational maintenance behaviors on marital satisfaction: A longitudinal analysis. The Journal of Family Communication, 1, 265-279.

Wenzel, M., Woodyatt, L., \& Hedrick, K. (2012). No genuine self-forgiveness without accepting responsibility: Value reaffirmation as a key to maintaining positive selfregard. European Journal of Social Psychology, 42, 617-627.

Whisman, M. A., \& Snyder, D. K. (2007). Sexual infidelity in a national survey of American women: Differences in prevalence and correlates as a function of method of assessment. Journal of Family Psychology, 21, 147-154.

Witvliet, C. V. O., Hinman, N. G., Exline, J. J., \& Brandt, T. (2011). Responding to our own transgressions: An experimental writing study of repentance, offense rumination, self-justification, and distraction. Journal of Psychology and Christianity, 30, 223-238

Wohl, M. J., \& McLaughlin, K. J. (2014). Self-forgiveness: The Good, the Bad, and the Ugly. Social and Personality Psychology Compass, 8, 422-435. 
Wohl, M. J., Pychyl, T. A., \& Bennett, S. H. (2010). I forgive myself, now I can study: How self-forgiveness for procrastinating can reduce future procrastination. Personality and Individual Differences, 48, 803-808.

Wohl, M. J., \& Thompson, A. (2011). A dark side to self-forgiveness: Forgiving the self and its association with chronic unhealthy behaviour. British Journal of Social Psychology, 50, 354-364.

Woodyatt, L., \& Wenzel, M. (2013). Self-forgiveness and restoration of an offender following an interpersonal transgression. Journal of Social and Clinical Psychology, 32, 225-259.

Woodyatt, L., Wenzel, M., \& de Vel-Palumbo, M. (2017). Working through psychological needs following transgressions to arrive at self-forgiveness. In L. Woodyatt, E. L. Worthington, M. Wenzel, \& B. J. Griffin (Eds.) Handbook of the psychology of self-forgiveness (pp. 43-58). Cham, Switzerland: Springer 


\begin{abstract}
APPENDIX
In the analyses discussed during the main portion of this dissertation, the positive variables clustered together and the negative variables clustered together. Resultantly, concerns exist regarding a possible social desirability effect and/or a possible positive and negative construct clustering effect related to acquiescent participant response patterns. It is important to note that research has consistently demonstrated that anonymous computer administered surveys have the strongest mitigating effects on social desirability effects in comparison to other self-report methods (e.g. Joinson, 1999). This also holds true for infidelity related research (e.g. Whisman \& Snyder, 2007). However, Antin and Shaw (2012) studied social desirability effects among U.S. and Indian MTurk participants and found that social desirability effects among U.S. MTurk users increase as monetary rewards increase. Partially in response to this concern, the monetary reward to MTurk participants in this study was kept purposefully low. Future research studies should include social desirability measures to mitigate or substantiate concerns regarding a social desirability effect. In future research, to mitigate a possible positive and negative construct clustering effect related to acquiescent participant response patterns, construct measurements should include an equal number of positively worded and negatively worded items.

Another concern related to this study is that multiple variables within this study had high collinearity (e.g. the correlation between satisfaction and closeness was .82; the correlation between positive maintenance behaviors and closeness was .79; the
\end{abstract}


relationship between negative maintenance behaviors and negative affect was .69). While concerns regarding the measurement of closeness were already discussed in the main discussion section of this dissertation, it is important to point out that future research should further delineate whether study variables utilized in this research project should continue to be used separately, or if they share considerable variance making them difficult to distinguish. The collinearity of positive and negative study measures within this study may also contribute to the study findings.

\section{Discussion of Additional Analyses}

In order to investigate possible alternative explanations (e.g. social desirability effect, positive and negative construct clustering effect related to acquiescent participant response patterns) regarding study findings, additional analyses were conducted to further investigate the obtained results. Means of self-forgiveness constructs as a function of demographic variables are reported in Table 4. Correlations of demographic variables with control and study variables are reported in Table 5. Intercorrelations of control variables are reported in Table 6.

To investigate the impact control variables had on the obtained results, the hypothesized path model was run without the inclusion of control variables. A path from self-punitiveness to negative maintenance behaviors was added to the path analysis to reach acceptable model fit (see Figure 6). Overall, this analysis did not indicate significant changes to conclusions drawn in the main portion of the paper. The relationship between genuine self-forgiveness and relationship satisfaction was still mediated by positive affect and closeness, and the relationship between pseudo selfforgiveness and relationship satisfaction, and self-punitiveness and relationship satisfaction was still mediated by negative affect, closeness, and negative maintenance 
behaviors. This suggests that the control variables used in this study did not have a major impact on study findings.

Path analyses were conducted separately for individuals whose partners know of the affair (see Figure 7) and individuals whose partners do not know of the affair (see Figure 8). Results indicate the same paths and similar effect sizes from self-forgiveness to relationship satisfaction for both groups. Results for these path analyses are in line with conclusions drawn in the main portion of the paper. Thus, whether a participant's partner knows of the affair did also not significantly influence study findings.

Path analyses were also conducted separately for females (see Figure 9) and males (see Figure 10). It is noteworthy to mention that the correlation between self-punitiveness and pseudo self-forgiveness was .00 for women and .30 for men. In this sample, women who engaged in pseudo self-forgiveness were less likely to experience feelings/behaviors of self-punitiveness than men. A potential explanation could be that women who engaged in pseudo self-forgiveness may have experienced less responsibility taking than men, thus statistical analyses did not indicate a correlation between self-punitiveness and pseudo self-forgiveness for women in this sample.

Additionally, the direct path from genuine self-forgiveness to positive maintenance behaviors was insignificant for men, but significant for women. The relation between genuine self-forgiveness and positive maintenance behaviors was fully mediated by positive affect and closeness for men, but only partially mediated by positive affect and closeness for women. The fact that somewhat different patterns of relationships between study variables were found for males and females provides evidence for differential validity. Thus, concerns related to social desirability effects or positive and 
negative construct clustering effects related to acquiescent participant response patterns are somewhat mitigated by this finding.

The conducted analyses indicate that it may be worth further exploring differences among men and women in relation to factors that lead toward engagement in various self-forgiveness processes. Additionally, it may be worth exploring differences among men and women in relation to how self-forgiveness may impact behaviors. Regardless, positive affect and closeness mediated the relationship between relationship satisfaction and genuine self-forgiveness for men and women. Additionally, negative affect, closeness, and negative maintenance behaviors mediated the relationship between relationship satisfaction and self-punitiveness, and relationship satisfaction and pseudo self-forgiveness for men and women. This is in line with conclusions drawn in the main portion of the paper. 


\section{Additional Tables with Demographic Information}

Table 4. Means of self-forgiveness constructs as a function of demographic variables

\begin{tabular}{lccc}
\hline & $\begin{array}{c}\text { Genuine self- } \\
\text { forgiveness }\end{array}$ & $\begin{array}{c}\text { Pseudo self- } \\
\text { forgiveness }\end{array}$ & $\begin{array}{c}\text { Self- } \\
\text { punitiveness }\end{array}$ \\
\hline Male (N=234) & 36.94 & 21.29 & 28.75 \\
Female (N=215) & 38.49 & 18.66 & 24.95 \\
Heterosexual (N=361) & 37.37 & 19.14 & 26.02 \\
Bisexual (N=75) & 39.36 & 24.23 & 31.48 \\
Lesbian (N=7) & 35.14 & 18.71 & 30.71 \\
Gay (N=5) & 39.80 & 19.20 & 28.80 \\
$\begin{array}{l}\text { Partner knows of the } \\
\text { affair (N=228) }\end{array}$ & 39.27 & 20.25 & 27.79 \\
$\begin{array}{l}\text { Partner does not know of } \\
\text { the affair (N=225) }\end{array}$ & 36.19 & 19.70 & 26.15 \\
$\begin{array}{l}\text { Emotional Infidelity } \\
\text { (N=92) }\end{array}$ & 38.83 & 19.80 & 25.71 \\
$\begin{array}{l}\text { Sexual Infidelity (N=159) } \\
\text { Sexual and Emotional }\end{array}$ & 36.91 & 17.28 & 29.29 \\
\begin{tabular}{l} 
Infidelity (N=202) \\
\hline
\end{tabular} & 37.90 & 2.17 & 29.66 \\
\hline
\end{tabular}


Table 5. Correlations of demographic variables with control and study variables

\begin{tabular}{|c|c|c|c|c|c|c|}
\hline & Female & Male & $\begin{array}{l}\text { Hetero- } \\
\text { sexual }\end{array}$ & $\begin{array}{l}\mathrm{Bi}- \\
\text { sexual }\end{array}$ & Age & $\begin{array}{l}\text { Time passed } \\
\text { since affair }\end{array}$ \\
\hline EI & $-.16^{* *}$ & $.12 *$ & .00 & -.01 & .05 & .07 \\
\hline SI & .07 & -.05 & -.03 & .05 & .05 & .06 \\
\hline ESI & .03 & -.04 & .02 & -.04 & -.08 & $-.11 *$ \\
\hline $\mathrm{AD}$ & .02 & -.02 & -.05 & .09 & .07 & $.27 * * *$ \\
\hline RD & $.20 * * *$ & $-.20 * * *$ & $.12 * *$ & $-.12 *$ & $.60 * * *$ & -.01 \\
\hline PK & .03 & -.04 & .08 & -.07 & $.10^{*}$ & -.05 \\
\hline GS & .09 & $-.10^{*}$ & -.09 & .09 & -.04 & -.07 \\
\hline SP & $-.17 * * *$ & $.17 * * *$ & $-.17 * * *$ & $.18 * * *$ & $-.19 * * *$ & .06 \\
\hline PS & $-.14 * *$ & $.16^{* *}$ & $-.19 * * *$ & $.22 * * *$ & $-.11 *$ & $.10^{*}$ \\
\hline PA & $-.16^{* *} *$ & $.16^{* *}$ & $-.10 *$ & $.11 *$ & $-.10 *$ & .06 \\
\hline NA & $-.16^{* *}$ & $.16^{* *}$ & $-.30 * * *$ & $.30 * * *$ & $-.17 * * *$ & .08 \\
\hline $\mathrm{C}$ & .03 & -.04 & $-.12 *$ & $.15^{* *}$ & -.08 & -.06 \\
\hline PMB & .09 & -.09 & $-.12 *$ & $.15^{* *}$ & -.09 & -.04 \\
\hline NMB & $-.20 * * *$ & $.20 * * *$ & $-.26 * * *$ & $.29 * * *$ & $-.16^{* *}$ & .09 \\
\hline $\mathrm{RS}$ & -.01 & .00 & .02 & .01 & -.07 & -.05 \\
\hline
\end{tabular}

Note. $\mathrm{N}=453, * p<.05, * * p<.01, * * * p<.001 . \mathrm{EI}=$ Emotional Infidelity, SI = Sexual Infidelity, ESI = Emotional and Sexual Infidelity, AD = Affair Duration, RD = Relationship Duration, PK = Partner Knows of the Infidelity, GS = Genuine SelfForgiveness, $\mathrm{SP}=$ Self-Punitiveness, $\mathrm{PS}=$ Pseudo Self-Forgiveness, $\mathrm{PA}=$ Positive Affect, NA = Negative Affect, $\mathrm{C}=$ Closeness, $\mathrm{PMB}=$ Positive Maintenance Behaviors, $\mathrm{NMB}=$ Negative Maintenance Behaviors, RS $=$ Relationship Satisfaction . 
Table 6. Intercorrelations of control variables

\begin{tabular}{lccccc}
\hline & 1 & 2 & 3 & 4 & 5 \\
\hline $1 . \mathrm{EI}$ & - & & & & \\
$2 . \mathrm{SI}$ & - & - & & & \\
$3 . \mathrm{ESI}$ & - & - & - & & \\
$4 . \mathrm{AD}$ & -.04 & $.22 * * *$ & $-.18 * * *$ & - & - \\
$5 . \mathrm{RD}$ & -.06 & $.09 *$ & -.04 & $.11 *$ & .07 \\
$6 . \mathrm{PK}$ & $.13 * *$ & $-.17 * * *$ & .06 & -.08 &
\end{tabular}

Note. $\mathrm{N}=453,{ }^{*} p<.05, * * p<.01 * * * p<.001 . \mathrm{EI}=$ Emotional Infidelity, $\mathrm{SI}=$ Sexual Infidelity, ESI = Emotional and Sexual Infidelity, AD = Affair Duration, RD = Relationship Duration, PK = Partner Knows of the Infidelity. Correlations between EI, SI, and ESI are not reported because participants only fit into one category. 


\section{Additional Path Analyses}

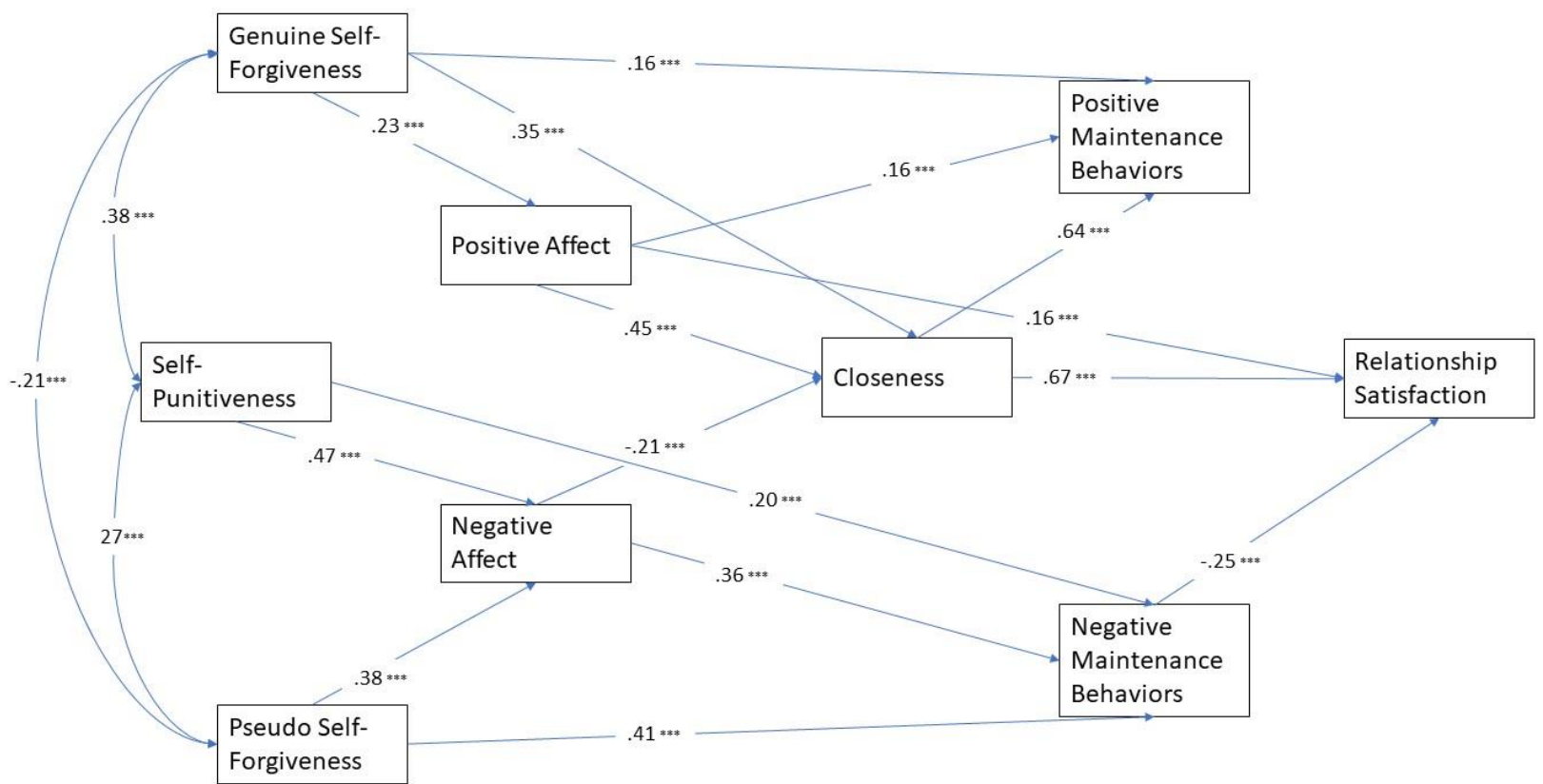

Figure 6. Path model analysis without correction by the control variables. $* * *$ indicates significance at the $p<.001$ level.

The model had acceptable fit to the data with $\chi^{2}(18)=95.11, p<.001, \mathrm{CFI}=.967$, $\mathrm{TLI}=.934, \mathrm{RMSEA}=.097$, PClose $<.001$. In comparison to the model used to answer hypothesis 2 , a path from self-punitiveness to negative maintenance behaviors $(\beta=.20, p$ $<.001)$ was added to reach acceptable model fit. 


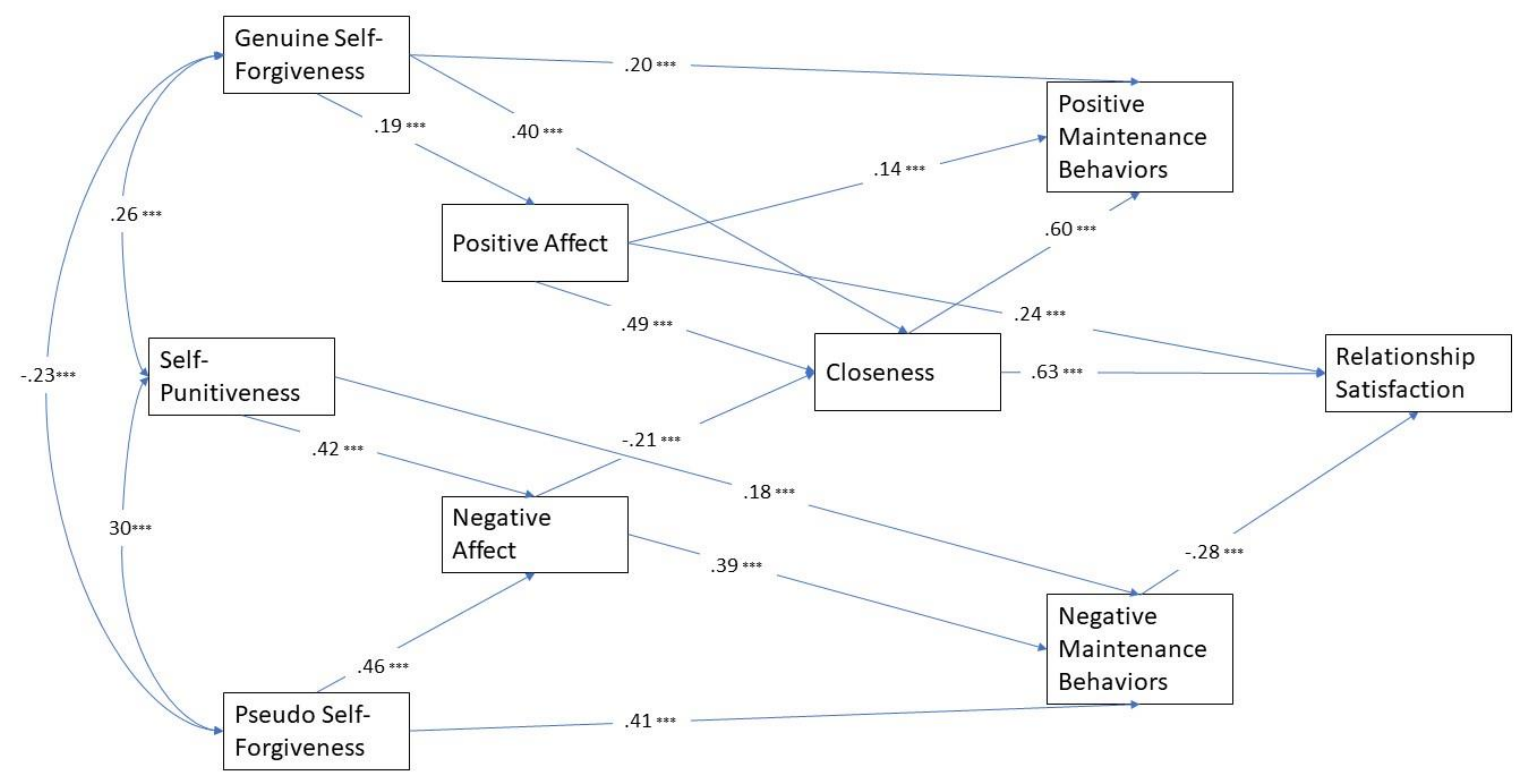

Figure 7. Path model analysis for individuals whose partners know of the affair. *** indicates significance at the $p<.001$ level.

The model had acceptable fit to the data with $\chi^{2}(18)=60.06, p<.001$, CFI $=.966$, $\mathrm{TLI}=.931, \mathrm{RMSEA}=.01$, PClose $=.002$. In comparison to the model used to answer hypothesis 2 , a path from self-punitiveness to negative maintenance behaviors $(\beta=.18, p$ $<.001)$ was added to reach acceptable model fit. 


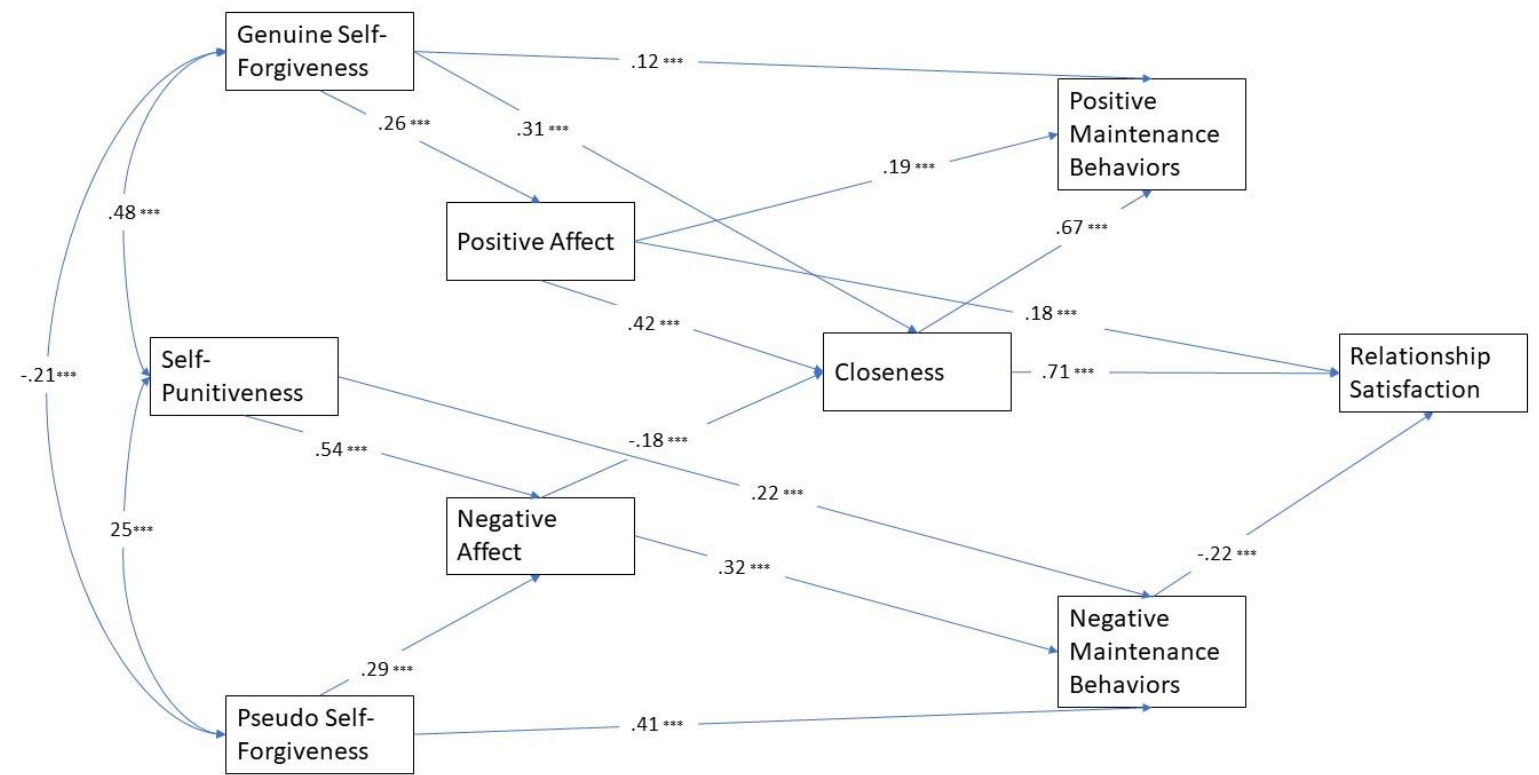

Figure 8. Path model analysis for individuals whose partners do not know of the affair. $* * *$ indicates significance at the $p<.001$ level.

The model had acceptable fit to the data with $\chi^{2}(18)=53.66, p<.001$, CFI $=.968$, $\mathrm{TLI}=.936, \mathrm{RMSEA}=.094$, PClose $=.007$. In comparison to the model used to answer hypothesis 2 , a path from self-punitiveness to negative maintenance behaviors $(\beta=.22, p$ $<.001)$ was added to reach acceptable model fit. 


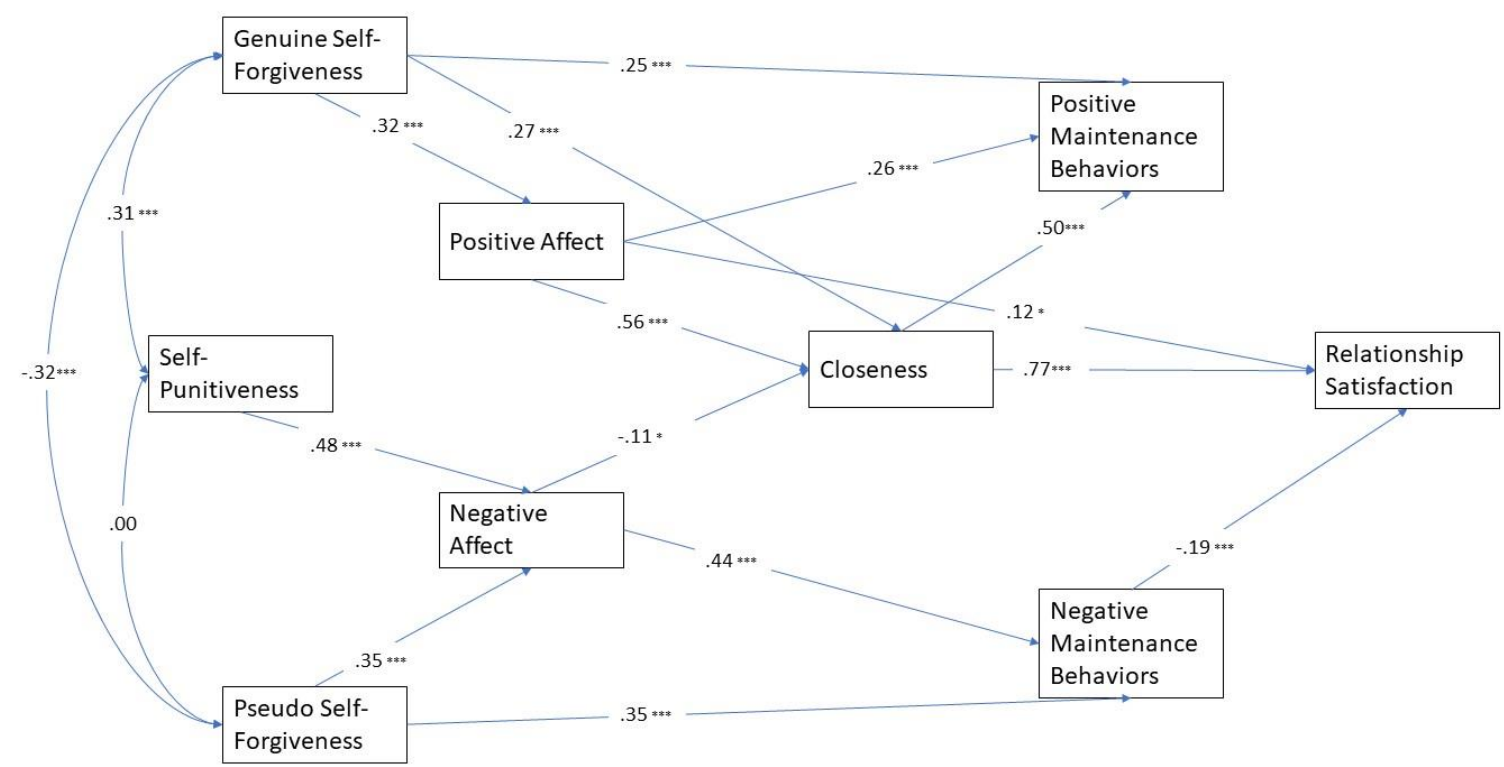

Figure 9. Path model analysis for females (Note: Only individuals identifying as heterosexual were used to avoid confounds). * indicates significance at the $p<.05$ level, $* * *$ indicates significance at the $p<.001$ level.

The model had acceptable fit to the data with $\chi^{2}(19)=48.85, p<.001$, CFI $=.964$, $\mathrm{TLI}=.933, \mathrm{RMSEA}=.097$, PClose $=.01$. No model modifications were made to reach acceptable model fit. 


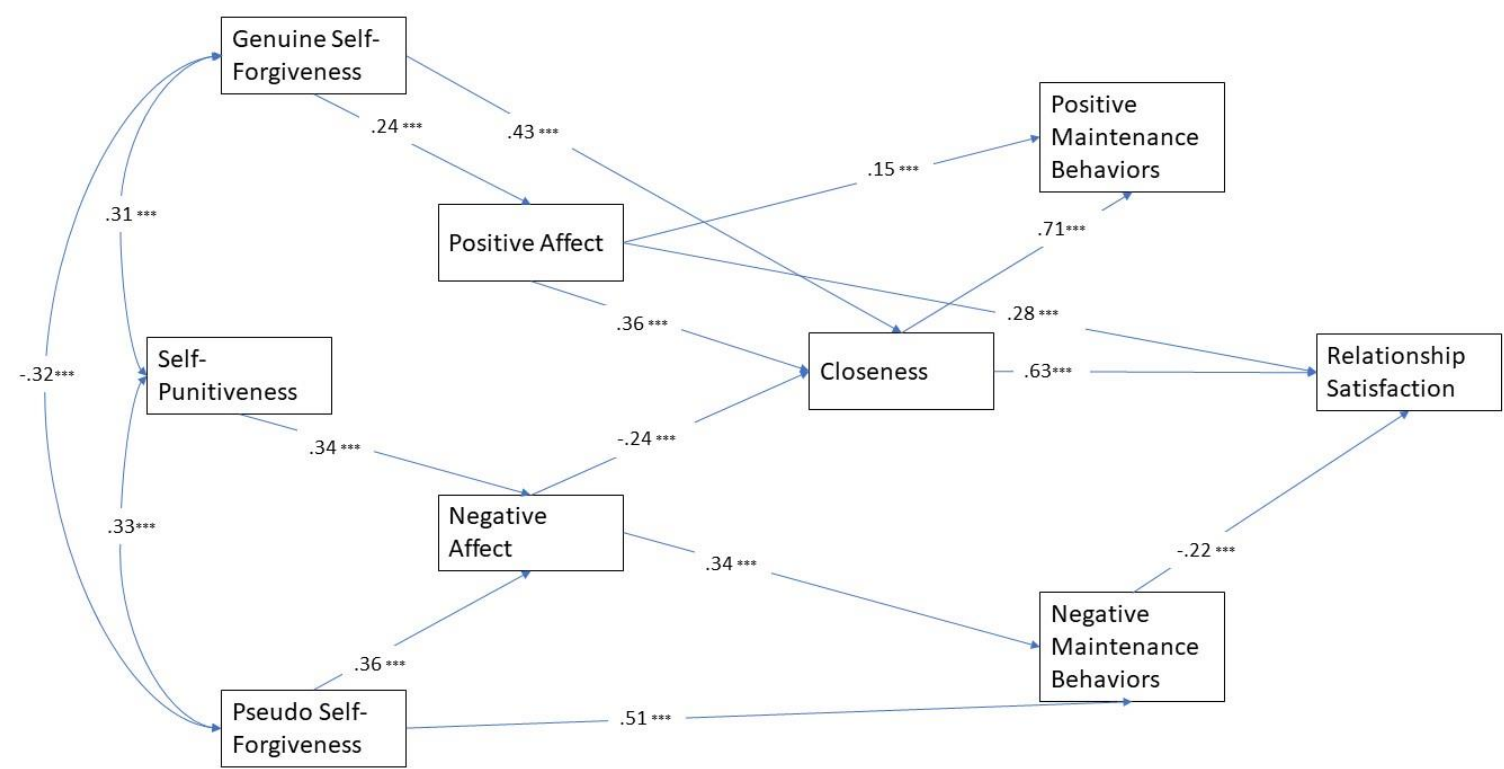

Figure 10. Path model analysis for males (Note: Only individuals identifying as heterosexual were used to avoid confounds). $* * *$ indicates significance at the $p<.001$ level.

The model had acceptable fit to the data with $\chi^{2}(20)=58.64, p<.001, \mathrm{CFI}=.958$, $\mathrm{TLI}=.924, \mathrm{RMSEA}=.10$, PClose $=.003$. The direct path from genuine self-forgiveness to positive maintenance behaviors was removed from the model because it was nonsignificant $(\beta=.09, p=.08)$. Otherwise, no model modifications had to be made in comparison to the path model used to answer hypothesis 2 . 


\section{CURRICULUM VITAE}

\section{Dominic Schmuck, M.Ed.}

2838 Taylor Blvd. | Louisville, KY 40208

(801) 644-6566 | dominic.schmuck@louisville.edu

\section{EDUCATION}

Ph.D. Counseling Psychology (APA Accredited)

Expected University of Louisville, Louisville, KY

Aug $2020 \quad$ Advisor: Mark Leach, Ph.D.

Dissertation: The Influence of Self-Forgiveness on Relationship

Satisfaction Post-Infidelity

M.Ed. Counseling Psychology

Dec $2016 \quad$ University of Louisville, Louisville, KY

Advisor: Mark Leach, Ph.D.

B.S. Psychology (Valedictorian), Minors: Statistics \& Family Life

June 2014 Brigham Young University, Provo, UT

\section{CLINICAL EXPERIENCE}

2018 - Current

2018
Associates in Counseling and Psychotherapy

New Albany, IN

Agency Type: Group Private Practice

Supervisors - Jessica Huett, Psy.D., Linda Burke, M.Ed.

- Work as a full-time therapist with Medicaid, Medicare, and DCS clients

- Provide CBT and ACT to individuals ranging in age from $14-$ 65

- Conduct psychodiagnostic assessments with children, adolescents, and adults. Write integrated assessment reports

- Complete DCS requested assessments to determine appropriate treatment and services for individuals who have been abusive, and/or who were abuse survivors

\section{Couple and Family Clinic - Kent School of Social Work} Louisville, KY

Agency Type: Community Mental Health Center

Supervisor - Laura Frey, Ph.D. 
- Conduct evidence-based co-couple therapy with a Social Work student, while being supervised live (via video camera and microphone) by other students and Dr. Frey.

- Participate in live supervision of other therapists conducting couple or family therapy

- Provide feedback to therapists during mid-session breaks and immediately after therapy sessions

Kentucky Correctional Institution for Women

Louisville, KY

Agency Type: Forensic (Prison)

Supervisor - Brian King, Psy.D.

- Provide CBT and ACT based individual and group therapy to inmates

- Conduct CPT treatment to inmates suffering from PTSD.

- Conduct mental status examinations and psychodiagnostic assessments to improve treatment outcome

- Conduct crisis interventions with inmates dealing with suicidal thoughts and/or recent suicide attempts

- Work as part of an interdisciplinary team consisting of psychiatric nurse practitioners, social workers, psychologists, and nurses

\section{Cardinal Success Program @ Nia Center}

Louisville, KY

Agency Type: Community Mental Health Center

Supervisors - Katy Hopkins, Ph.D., Eugene Foster, Ed.D., Patrick Pössel, Ph.D.

- Conduct psychodiagnostic assessments with children, adolescents, and adults (clients' age range was $3-76$ ), regarding possible learning disorders, ADHD, Autism Spectrum Disorder, and various personality disorders

- Write integrated assessment reports

- Conduct CBT and ACT based treatments with low socioeconomic status and underserved community clients

- Consult with fellow students regarding treatment planning and best treatment practices

- Routinely administer outcome assessments to track client progress

\section{Spalding University Counseling Center}

Louisville, KY Agency Type: University Counseling Center Supervisor - Allison From-Tapp, Psy.D.

- Assess college students for learning disorders, ADHD, psychotic symptoms, mood disorders, personality disorders, 
and trauma related disorders, using a variety of assessment batteries

- Write integrated reports to present to students and, if appropriate, to the Spalding University Resource Center

- Conduct semi-structured intake assessments

- Provide CBT and ACT to students and staff

- Routinely administer outcome assessments to track client progress

- Participate in weekly case management meetings, individual supervision, and group supervision

- Participate in and organize outreach events with fellow practicum students

Cedar Lake Lodge, Residential Treatment Center LaGrange, KY Agency Type: Residential Treatment Facility Supervisor - Jeffrey Hicks, Ph.D.

- Conduct a variety of intellectual, achievement, and adaptive assessments for residents diagnosed with mild to severe intellectual disability

- Write integrative reports regarding residents' continuing treatment necessity and adjustment

- Provide consultation to direct caretakers and staff members

- Work as part of an interdisciplinary team with a psychiatrist, speech-language pathologists, physical therapists, nurses, and behavioral specialists

- Participated in weekly individual and group supervision and occasional training seminars

$2015-2016$

\section{Indiana University Southeast Counseling Center} New Albany, IN

Agency Type: Counseling Center

Supervisor - Michael Day, Psy.D.

- Conduct intake assessments and outcome assessments, and provide evidence based individual and couple therapy to traditional and non-traditional students (ages 18 - 46)

- Provide crisis intervention for suicidal and/or recently traumatized individuals

- Consult with students regarding their professional and academic goals

- Aid students in navigating campus specific and community wide resources available to them. E.g. accessing resources for learning or developmental disabilities, tutoring, and contacting Child Protective Services 
- Participate in outreach efforts in classrooms and the Indiana University Southeast community to educate about mental health and UCC services

\section{COMPLETED TRAININGS}

2019

2017

2017

2017

2017

2017

2017

2016

2016

2016

2015

2015
Human Trafficking Training for Providers (HT 301); Kate Berryman, LPC, NBCC, MS

Online Training Course for Cognitive Processing Therapy; Medical University of South Carolina

Online Training Course for Aggression and Domestic Violence;

Massachusetts General Hospital, Department of Psychiatry

Mandated Reporters; Critical Links in Protecting Children in Georgia, Carla S. Rogg, MSW

C-SSRS Initial Training; Kelly Posner, Ph.D.

Mindfulness exercises in practice; Robin From-Tapp, Ph.D.

LGBTQ Client treatment; Allison From-Tapp, Ph.D.

Online Trainings for Military Culture: Core Competencies for Healthcare Professionals; Department of Veterans Affairs, Employee Education System and Mental Health Services, \& Department of Defense (DoD)

- Self-Assessment and Introduction to Military Ethos

- Military Organization and Roles

- Stressors and Resources

- Treatment, Resources, and Tools

Neuropsychology for the Non-Neuropsychologist; Bradley S. Folley, Ph.D., ABPP, \& Rebecca L.H. Stilp, Ph.D.

Safe Zone Training; Megan Kahn, Ph.D.

Online Training Course for Trauma-Focused Cognitive-Behavioral Therapy; Medical University of South Carolina

Brief Alcohol Screening and Intervention of College Students (BASICS): A Harm Reduction Approach 


\section{TEACHING EXPERIENCE}

$2015-2017$

2016

2013

2012

\section{RELEVANT WORK EXPERIENCES}

2014 - Current Researcher

University of Louisville, Department of Counseling and Human

Development, Louisville, KY

Supervisor - Mark Leach, Ph.D.

Personal Duties: Create studies on the relational impact of

perpetrators' self-forgiveness and victims' forgiveness after infidelity; write IRB applications; recruit participants; independently perform 
data analyses; prepare and revise findings for presentation and publication

$2017-2018 \quad$ Graduate Outreach Coordinator

University of Louisville Counseling Center, Louisville, KY

Supervisor - Aesha Uqdah, Psy.D.

Personal Duties: Organize, coordinate, and implement outreach efforts to the UofL Community; provide presentations to the campus community on stress, depression, anxiety, dealing with loss, suicide, and many other mental health related topics; participate in tabling events to introduce UCC services; maintain social networking sites

2014 - $2015 \quad$ Graduate Research Assistant

University of Louisville, Department Special Education, Louisville, KY

Supervisor - Timothy Landrum, Ph.D.

Personal Duties: Primary data analyst for a study on teacher perceptions; consult with Special Education faculty regarding research projects; write and edit articles in preparation for publication; conduct literature reviews and screen articles for systematic reviews

$2013-2014 \quad$ Research Assistant - Psychotherapy Treatment Outcomes Brigham Young University, Department of Education, Provo, UT Advisor - Timothy Smith, Ph.D.

Personal Duties: Review and screen empirical studies on psychotherapy outcome for a meta-analysis; prepare a comprehensive review of alliance in psychotherapy

2013 - $2014 \quad$ Research Assistant - Stress and Psychotherapy Outcome Team Brigham Young University, Department of Psychology, Provo, UT Advisor - Patrick Steffen, Ph.D.

Personal Duties: Lead an experimental research project regarding physiological stress and psychotherapy outcome; write IRB application lead research meetings and train RAs on research procedures; collect and analyze data, conduct literature reviews; prepare project findings for presentation and publication

2012 - $2013 \quad$ Utah Family Academy Intern

ACAFS - The Family Academy, Provo, UT

Supervisor - Jay Jensen, Ph.D.

Personal Duties: Supervise court ordered parent-child visitations and keep detailed record; facilitate appropriate behavior during visitations; interview children about their experience

2011 - $2012 \quad$ Research Team Member - ASD Emotion Regulation Lab Brigham Young University, Department of Psychology, Provo, UT 
Advisor - Mikle South, Ph.D.

Personal Duties: Analyze data; contact participants and schedule appointments; participate in research development and revision; prepare research findings for presentations

\section{SERVICE}

$2017-2018 \quad$ Student Resources Social Media Committee Member

University of Louisville, Louisville, KY

Personal Duties: Participate in monthly meetings to review UofL social media activities and discuss means of improving student engagement in campus activities

Post-Doc hiring Committee Member

Spalding University Counseling Center, Louisville, KY

Personal Duties: Interview and review applicants for a post-doc

Psychologist position

Graduate Poster Judge

2017 Spring Academic Conference, Louisville, KY

Personal Duties: Rate graduate student poster presentations; provide feedback to graduate students about their presentations

2015 - $2017 \quad$ Youth Leader and Instructor

Non-Profit Organization, Louisville, KY

Personal Duties: Instruct Christian youth from underserved neighborhoods on healthy family life, morality, safe behavior, and Christianity; organize bi-monthly activities to gather in a safe environment and form healthy bonds

2016

Assessment Administrator Volunteer

University of Louisville, Department of Counseling and Human

Development, Louisville, KY

Supervisor - Jill Adelson, Ph.D.

Personal Duties: Participate in a large scale $\$ 1,199,121$ grant project by administering the Naglieri Non-Verbal Ability Test (NNAT) to K $3^{\text {rd }}$ graders

2015 - 2016 Graduate Student Council Representative for the Department of Counseling and Human Development (ECPY)

University of Louisville, Louisville, KY

Personal Duties: Communicate ECPY needs to the Graduate Student

Council; aid ECPY students in applying for research and travel

funding; participate in meetings regarding University wide policies 

Development, Louisville, KY

Personal Duties: Navigate relationships of DSO with fellow students; advise the DSO president regarding organizational development

Applicant Interviewer: Counseling Psychology M.Ed. program University of Louisville, Department of Counseling and Human Development, Louisville, KY Supervisor - Mark Leach, Ph.D. Personal Duties: Interview applicants to the Counseling Psychology M.Ed. program; consult regarding admission decisions

$2014-2015$ Doctoral Student Organization Member University of Louisville Personal Duties: Attend monthly meetings and research talks; provide feedback to faculty regarding program related issues and student questions; actively engaged in community service and activities. disorders; encourage patients to participate in daily activities; facilitate appropriateness of patients' behaviors

\section{RESEARCH PRESENTATIONS}

Huckaby, L., Schmuck, D. G, \& Leach M. M. (2017, April). Process Model of SelfForgiveness Responses as Predictors of Relationship Satisfaction. Poster presented at the $30^{\text {th }}$ Annual Great Lakes Regional Counseling Psychology Conference, Muncie, Indiana.

Schmuck, D. G., Huckaby, L., \& Leach, M. M. (2017, April). Self-Forgiveness: A Perpetrator's Way of Improving Relationships Post Infidelity. Poster presented at the $30^{\text {th }}$ Annual Great Lakes Regional Counseling Psychology Conference, Muncie, Indiana.

Kuo, P., Watterson, K., Schmuck, D. G., Cauley, B., Roane, S., \& Leach, M. (2016, August). Research Mentor Attrition and Psychology Doctoral Students' Academic Outcomes and Mental Health. Poster presented at the $124^{\text {th }}$ Annual APA Convention, Denver, Colorado.

Schmuck, D. G. \& Leach, M. M. (2016, August). The Relational Impact of Perpetrator's Infidelity Related Self-Forgiveness. Poster presented at the $124^{\text {th }}$ Annual APA Convention, Denver, Colorado. 
Pennington, R. C. \& Schmuck, D. G. (2015, May). Frequency of Mand Instruction and Contextual Variables reported in Behavioral, Special Education and Speech Journals. Poster presented at the ABAI 41st Annual Convention, San Antonio, Texas.

Pennington, R. C., Schmuck, D. G., Burt, J. L., Ferguson, L., \& Ault, M. J. (2015, April). Frequency of Mand Instruction and Contextual Variables reported in Behavioral, Special Education and Speech Journals. Poster presented at the Annual KYABA Conference, Louisville, Kentucky.

Schmuck, D. G. \& Leach, M. M. (2015, March). Extradyadic involvement in romantic relationships: The influence of forgiveness and self-forgiveness on future relationships. Poster presented at the $28^{\text {th }}$ Annual Great Lakes Regional Counseling Psychology Conference, Muncie, Indiana.

Schmuck, D. G. \& Zhang, M. (2015, March). Marital education and its discontents. Paper presented at the SEPA $61^{\text {st }}$ Annual Meeting, Hilton Head, South Carolina.

Fidalgo, L., Schmuck, D., \& Breton, B. (2014, March). Physiological stress and psychotherapy outcome. Poster presented at the AAPB $45^{\text {th }}$ Annual Scientific Meeting, Savannah, Georgia.

Schmuck, D., \& Zhang, M. (2014, March). Self-forgiveness as an infidelity intervention. Poster presented at the Annual IAMFT Conference, Naperville, Illinois.

Schmuck, D., Flack, D., Riley, C., \& South, M. (2013, April). Academic Competitiveness Measure. Poster presented at the Mary Lou Fulton Mentored Research Conference, Provo, Utah.

Schmuck, D. (2013. January). Single parenting: Fewer negative effects on children's behaviors than claimed. Paper presented at the International Student Research Symposium. Online Symposium.

Chamberlain, P., Newton, T., White, S., Schmuck, D., Bjornn, D., Rodgers, J., Wigham, S., Gray,L., Kirwan, B. \& South M. (2012, May). Rotational vs. emotional decision making in autism: Evidence from the Iowa Gambling Task. Poster presented at the International Meeting for Autism Research, Toronto, Ontario, Canada.

White, S., Chamberlain, P., Newton, T., Ernst, W., Schmuck, D., South, M. (2012. April). Rotational vs. emotional decision making in autism: evidence from the Iowa Gambling Task. Poster presented at the Mary Lou Fulton Mentored Research Conference, Provo, Utah. 
Zhang, M., Schmuck, D., \& Gonzalez, T. (2012. April). Connecting lifelong learning and service in the classroom. Paper presented at the International Conference on College Teaching and Learning, Ponte Vedra Beach, Florida.

White, S., Chamberlain, P., Newton, T., Ernst, W., Schmuck, D., South, M. (2011. October). Rotational vs. emotional decision making in autism: Evidence from the Iowa Gambling Task. Poster presented at the Neuroscience Snowbird Symposium, Salt Lake City, Utah.

\section{PUBLICATIONS}

Pennington, R. C., Ault, M. J., Schmuck, D. G., Burt, J. L., \& Ferguson, L. L. (2016). Frequency of mand instruction and contextual variables reported in behavioral, special education, and speech \& language journals. Behavior Analysis in Practice, 9 235-242. doi:10.1007/s40617-015-0095-7

Pennington, R. C. \& Schmuck, D. G. (2015). Promising computer-based context for teaching social skills warrants further investigation. Evidence-Based Communication Assessment and Intervention, 2, 58-61. doi:10.1080/17489539.2014.993493.

Steffen, P. R., Fidalgo, L., Schmuck, D. G., Tsui, Y., \& Brown, T. (2014). Psychotherapy participants show increased physiological responsiveness to a lab stressor relative to matched controls. Frontiers in Psychology, 5. doi:10.3389/fpsyg.2014.00795

\section{HONORS AND AWARDS}

2017

2017

2016

2016

2015

2014

2013
Faculty Favorites Award (award nominations are made by UofL students), University of Louisville

Pass with Honors in Orals Comprehensive Examinations, Department of Counseling and Human Development, University of Louisville

Travel Award, American Psychology Association

Travel Grant, University of Louisville, Graduate Student Council

Semi-Finalist for Graduate Student Award, SEPA $61^{\text {st }}$ Annual Meeting

Valedictorian, Brigham Young University, Department of Psychology

Court Ordered Supervisor of the Year, Utah Family Academy, ACAFS, Provo, UT 
$2012-14$

Full Tuition Scholarship for Academic Excellence, Brigham Young University

2012, 14 Travel Grant, Brigham Young University, Department of Psychology

2012, 14 Travel Grant, Brigham Young University, College of Family, Home, and Social Sciences

2011, 12, 14 Deans List, Brigham Young University, College of Family, Home, and Social Sciences

\title{
LANGUAGES
}

English (fluent)

German (native)

\section{REFERENCES}

Mark M. Leach, Ph.D.

Department Chair, Professor

Department of Counseling \&

Human Development

University of Louisville

Phone: (502) 852-0588

Email: m.leach@louisville.edu

\author{
Allison E. From-Tapp, Psy.D. \\ Director, Licensed Psychologist \\ Spalding University \\ Counseling and Psychological \\ Services (CAPS) \\ Phone: (502) 550-8473 \\ Email: afrom@spalding.edu \\ Brian King, Psy.D. \\ Program Administrator, \\ Licensed Psychologist \\ Kentucky Correctional \\ Institution for Women \\ Phone: (502) 241-8454 \\ Email: brianj.king@ky.gov
}

